\title{
Metabolic evolutionary roots of the macrophage immune response in amoeba-bacteria interactions: The conserved role of hypoxia-induced Factor and AMP kinase*
}

\author{
Jolanta M. Dzik® \\ Nencki Institute of Experimental Biology Polish Academy of Sciences, Warsaw, Poland\#
}

The bacteria Legionella, being able to infect both macrophages and protozoans, reduce oxidative phosphorylation and induce glycolysis, which allows pathogens to grow and replicate in these cells. In amoeba-like inflammatory macrophages (M1), the phagocytizing cells of the primary immune defense, an increase in the rate of glycolysis is followed by a decrease of oxidative phosphorylation. The opposite takes place in anti-inflammatory macrophages (M2). They change from glycolysis to oxidative metabolism when AMP-dependent kinase (AMPK) is activated by a high ratio of AMP/ATP. Stimulation of macrophages with anti-inflammatory cytokines causes activation of AMPK. Infection of macrophages with the parasitic flagellate Leishmania infantum induces a switch from an initial glycolytic phase to oxidative phase with the essential role of AMPK in this change. Activated AMPK induces catabolic pathways effectively producing ATP as well as processes requiring the energy supply. AMPK regulates the migration of cells and enhances the phagocytic activity of macrophages. In macrophages, bacterial products activate TLRs and NF-KB signaling, causing an increase of transcription of hypoxia-induced factor HIF-1a (a subunit of HIF-1). This brings about induction of the enzyme and transporter expression essential for glycolysis and the pentose phosphate pathway to proceed and makes biosynthetic processes and ROS production in macrophages possible. Hypoxia augments macrophage phagocytosis in a HIF-1a-dependent manner. Multicellular parasites experience changes in the availability of oxygen in their life cycle. In the nematode Ascaris suum, HIF participates in the pre-adaptation to hypoxic conditions after infection of their hosts. Also, the freshwater and marine invertebrates meet changes of oxygen concentrations. In the anaerobic branch of the respiratory chain of these invertebrates, fumarate serves as the terminal electron acceptor that is reduced to succinate in complex II of the ETC. In mammalian cells, accumulation of succinate under hypoxic conditions suggests that the mammalian complex II may reduce fumarate to succinate, too. The data reviewed here show that the ability to shift the cell metabolism towards glycolysis observed in activated macrophages can be traced back in evolution to metabolic changes characterizing protozoans infected with bacteria. Anabolic needs of multiplying bacteria direct host metabolism to glycolysis that produces, aside from ATP, precursors of the amino acids used by the pathogen for its protein synthesis. M1activated mammalian macrophages behave in the same way. Regulation of metabolism in M1 and M2 macrophages is further enhanced by HIF-1 and AMPK, respectively. These archaic functions of AMPK and HIF, important also to control phagocytosis and cell migration were extended to embryonic development in multicellular organisms.
Keywords: adaptation to hypoxia, bacterial infection, glycolysis, oxidative phosphorylation, parasite infection

Received: 03 May, 2021; revised: 24 June, 2021; accepted: 28 June, 2021; available on-line: 08 August, 2021

घe-mail: jolanta.m.dzik@gmail.com

\#Retired

*This paper is dedicated to Professor Wacław Tadeusz Szybalski on the 100th anniversary of his birth

\section{NATURE OF ENERGY AND BUILDING ELEMENTS PRODUCTION IN THE CELL IS UNIVERSAL}

Last years have introduced significant changes to our understanding of metabolic aspects of the immune cell's activation. The phagocytic macrophages of mammals have a long evolutionary history and are believed to preserve primary mechanisms of an immune response, found already in the sponge amoebocytes (ref. in Dzik, 2010). This review aims to show that the metabolic processes accompanying macrophage activation are evolutionary conserved and that homologous mechanisms act in all cells of multicellular organisms from embryogenesis to maturity.

The main metabolic demand necessary for surviving of all organisms is nutrient supply providing energy and building elements. The energy providing mechanisms depend on availability of the oxygen and fuel, mainly glucose, that degradation pathways are central throughout all domains of life. The two main metabolic routes for providing the energy in cells include anaerobic glycolysis (Embden-Meyerhof-Parnas pathway, EMP) and aerobic oxidative phosphorylation (oxphos), comprising citric acid cycle and respiratory chain complexes, with much higher efficiency than the former one. With limited oxygen supply cells depend on glycolysis for providing energy from carbohydrates. Without oxygen, glycolysis supplies 2 molecules of ATP and 2 pyruvates per one molecule of glucose. To recover the $\mathrm{NAD}^{+}$necessary for proceeding of glycolysis, pyruvate is reduced to lactate by lactate dehydrogenase in the lactic acid-producing bacteria, erythrocytes, and during exhaustive muscle cell contraction. Instead, in yeast, pyruvate is metabolized to ethyl alcohol by a two-step reaction catalyzed by pyruvate decarboxylase and alcohol dehydrogenase to obtain $\mathrm{NAD}^{+}$. In aerobic organisms in the presence of oxygen glycolysis is suppressed and oxidative phosphorylation enhanced. The main switch between both pathways depends on oxygen availability that is required to complete the oxphos processes. This phenomenon was named the Pasteur effect because it was Louis Pasteur who found in 
1857 that butyric acid fermentation is arrested when air is introduced to the fermenting fluid. The Pasteur effect is considered the most archaic autonomous adaptations of the cell to hypoxia during the anaerobic fermentation. Otto Warburg in 1947 found that cancer cells maintain a very high rate of glycolysis even in the presence of oxygen. The so-called Warburg effect can be considered as a loss of ability to use the Pasteur effect (Amoêdo et al., 2013).

Metabolic flow through glycolysis is controlled at three steps. Hexokinase is inhibited by its product glucose-6-P. Fructose-2,6-bisphosphate, AMP, and ADP are allosteric activators of phosphofructokinase whereas ATP, citrate, and $\mathrm{H}^{+}$inhibit the enzyme. Pyruvate kinase is activated by fructose-1,6-bisphosphate and inhibited by acetylCoA, ATP, and alanine. Overall, glycolysis slows down when the energy charge is high or the intermediates of the Krebs cycle are abundant. It is noteworthy that glycolytic intermediates give rise to several amino acids: Ser, Gly, Cys, Ala, Val, Leu, Try, Phe, Tyr, and glycerol, a precursor of triacylglycerols and glycerophospholipids.

Under conditions of lack or limitation of carbohydrates, glucose can be synthesized from noncarbohydrate compounds such as lactate, amino acids, and glycerol in the process of gluconeogenesis that is identical in all organisms (Romano \& Conway, 1996).

Glycolysis and gluconeogenesis are controlled reciprocally. The difference between glycolysis and gluconeogenesis concerns three steps regulated by substrate cycles. Glycolysis is regulated primarily by reactions catalyzed by hexokinase, phosphofructokinase, and pyruvate kinase. The opposite reactions in gluconeogenesis catalyzed by glucose-6-phosphatase, fructose-1,6-bisphosphatase, and the combination of pyruvate carboxylase and phosphoenolpyruvate carboxykinase control synthesis of glucose de novo. Fructose-1,6-bisphosphatase is inhibited by fructose-2,6-bisphosphate, AMP, and citrate. Pyruvate carboxylase is inhibited by ADP and stimulated by acetyl-CoA. The remaining reactions of gluconeogenesis are catalyzed by the glycolytic enzymes that drive reversible reactions in either direction according to mass action. Thus, the rates of glycolysis and gluconeogenesis depend mostly on the energy charge and nutrient status of the cells.

Ronimus and Morgan (Ronimus \& Morgan, 2003) have reviewed the present knowledge concerning the distribution and phylogeny of enzymes involved in the Embden-Meyerhof-Parnas pathway. The main metabolic pathway of glycolysis is found in all three domains of life, Archaea, Bacteria, and Eucarya, although a significant variability of enzymes, especially in the hyperthermophilic bacteria and in the Archaea occur. The genes encoding the enzymes of the lower portion of glycolysis (the trunk pathway), including triosephosphate isomerase, glyceraldehyde-3-phosphate dehydrogenase, phosphoglycerate kinase, and enolase, were all present before the divergence of the archaeal and bacterial domains, i.e. in the presumed last universal common ancestor (LUCA). The trunk pathway is essential for amino acid, pentose phosphate, and purine synthesis, therefore it is under rigorous evolutionary maintenance.

The enzymes of the trunk pathway are also common to the Entner-Doudoroff (ED) route that is widely distributed in bacteria where it can be a major pathway of glucose catabolism under aerobic conditions (Romano \& Conwey, 1996). In this pathway, glucose-6-phosphate is oxidized to 6-phosphogluconic acid with a concomitant reduction of NADP to NADPH. The 6-phosphogluconate is then dehydrated and split into glyceraldehyde- 3-phosphate and pyruvate. Glyceraldehyde-3-phosphate is catabolized, as in glycolysis, which results in the production of NADH and ATP molecules. Thus, glucose molecule catabolized through the ED pathway is degraded to two pyruvates finally yielding one ATP plus one NADPH and one NADH.

The universal occurrence of enzymes of the trunk pathway, in conjunction with their phylogeny, supports the concept that the glycolysis pathway evolved from the bottom up, following the direction of gluconeogenesis. In addition, sequence analysis of compartment-specific isoforms of triosephosphate isomerase and glyceraldehyde-3-phosphate dehydrogenases supports the idea that glycolytic enzymes of Eukaryota have been acquired from mitochondrial genomes (ref. in Liaud et al., 2000). Hexokinase, glucose phosphate isomerase, 6-phosphofructokinase, the enzymes of the upper portion of the EMP pathway, probably derived from various gene families occurring in hyperthermophiles and other Archaea (ref. in Ronimus \& Morgan, 2003).

Parallel to glycolysis is the pentose phosphate pathway (PPP) of glucose catabolism, which branches from the glycolysis at the glucose 6-phosphate step and operates in two phases; oxidative and nonoxidative. The oxidative phase results in the production of ribulose-5phosphate, $\mathrm{CO}_{2}$, and 2 moles of NADPH per glucose 6 -phosphate molecule. In a nonoxidative phase, some ribulose-5-phosphate is converted to ribose-5-phosphate. The synthesis of 5-carbon sugars is provided by a complex series of sugar interconversions. The enzymatic rearrangements in the non-oxidative phase with the participation of transketolase and transaldolase give two fructose 6-P molecules and one glyceraldehyde 3-P from the three pentose phosphates. The most important regulatory factor is the intracellular concentration of $\mathrm{NADP}^{+}$. NADPH competes with $\mathrm{NADP}^{+}$in binding to glucose 6-phosphate dehydrogenase (catalyzing oxidation of glucose-6-P to 6-phosphogluconolactone) and inhibits that enzyme. This reaction is rate-limiting for the pentose phosphate pathway and serves as the control point. The pentose phosphate pathway competes with glycolysis for glucose-6- phosphate. Whereas glycolysis is regulated chiefly by the energy status of the cell and fuel availability, flux through the PPP depends on the cellular $\left[\mathrm{NADP}^{+}\right] /[\mathrm{NADPH}]$ ratio. The pentose phosphate pathway is regulated also due to sedoheptulokinase (SHPK) activity (Kardon et al., 2008; Wamelink et al., 2008). The enzyme was known earlier under the name carbohydrate kinase-like (CARKL). SHPK phosphorylates sedoheptulose on the C7. The enzyme balances the S7P from the non-oxidative part of PPP and G3P from glycolysis. SHPK creates a second rate-limiting step in PPP aside from glucose-6-phosphate dehydrogenase. The PPP supplies NADPH and ribose 5-phosphate that are vital for the survival and proliferation of cells. NADPH acts as a reductant required for the synthesis of fatty acids, sterols, nucleotides, and non-essential amino acids, and the ribose-5-P is a building compound for nucleic acid synthesis. The PPP is recognized as a central player in controlling and maintaining the redox homeostasis of cells since NADPH serves as a cofactor for the reduction of oxidized glutathione (GSSG) to reduced glutathione $(\mathrm{GSH})$ via glutathione reductase. NADPH takes part in reactions of NADPH oxidase and nitric oxide synthase which produce reactive oxygen and nitrogen species respectively.

The oxidative branch of the PPP is not universal since it has not been found in many thermophilic and aerobic organisms (Bräsen et al., 2014). The oxidative branch is 
highly active in the majority of eukaryotes (Miclet et al., 2001). Reactions of the non-oxidative phase of PPP may have derived from pre-biotic metal-catalyzed interconversions of sugar phosphates in sequences that resemble glycolysis and the phosphate pathway. However, the interconversion of glucose 6-phosphate to 6-phosphogluconate, delineating the oxidative PPP, was not likely in the conditions of the prebiotic ocean (Keller et al., 2014). This suggests that the non-oxidative branch is older than the oxidative branch of the PPP pathway. Reactions of the non-oxidative PPP (with the overlapping Calvin Cycle and Entner-Doudoroff Pathways), take place nearly ubiquitously, and fulfill a central role to provide ribose 5 -phosphate for the nucleotide and nucleic acid synthesis, as well as erythrose 4-phosphate for the synthesis of aromatic amino acids.

In eukaryotic cells, pyruvate obtained from glycolysis is oxidized in mitochondria in the Krebs cycle, and $\mathrm{NADH}$ is reoxidized in the electron transport chain (ETC). Oxidative decarboxylation of pyruvate by the pyruvate dehydrogenase (PDH) complex in mitochondria gives acetyl-CoA entering the CAC. Acetyl-CoA condenses with oxaloacetate to form citrate. After one turn of the cycle, oxaloacetate is regenerated and the process takes place anew. During the citric acid cycle, reduced electron carriers (NADH and FADH2) are produced and their reoxidation in the ETC supplies energy for ATP synthesis. The citric acid cycle may supply biosynthetic intermediates as well. Oxaloacetate and $\alpha$-ketoglutarate are the $\alpha$-keto-acid analogs of the amino acids, that is aspartate and glutamate, and are used in the synthesis of these and other amino acids by transamination. In the cytosol, citrate transported from mitochondria is cleaved to oxaloacetate and acetyl-CoA, the latter being needed for the fatty acid biosynthesis. To replace these intermediates, anaplerotic reactions balance the loss of carbon from the cycle. Regulation of the citric acid cycle takes place at the level of fuel entry into the cycle (at the pyruvate dehydrogenase and the citrate synthase steps) as well as at the level of isocitrate dehydrogenase and $\alpha$ - ketoglutarate dehydrogenase reactions within the cycle. In mammals, the activity of the pyruvate dehydrogenase complex depends also on the phosphorylation/ dephosphorylation of the pyruvate dehydrogenase subunit. Allosteric interactions and concentration of substrates control flux through the cycle. The most important factor controlling the activity of the citric acid cycle is the intramitochondrial ratio of $\left[\mathrm{NAD}^{+}\right]$to $[\mathrm{NADH}]$. When $\left[\mathrm{NAD}^{+}\right] /[\mathrm{NADH}]$ ratio decreases, because of reduction of the oxygen supply, the low concentrations of $\mathrm{NAD}^{+}$may restrict activities of isocitrate dehydrogenase and $\alpha$-ketoglutarate dehydrogenase. Also, a high level of ATP slows down the activity of the Krebs cycle.

The tricarboxylic acid cycle is widespread among $\alpha$-proteobacteria, from which the mitochondria had derived (Thrash et al., 2011). The same version of the citric acid cycle characterizes virtually all organisms, including also anaerobic chemotrophs. Chemotrophs do not oxidase glucose for energy production but use an incomplete citric acid cycle both as a fermentative pathway and for biosynthesis. For these purposes, the last four reactions of the citric acid cycle are reversed in the direction from oxaloacetate to succinate. NADH for reduction of oxaloacetate to malate derives from the glyceraldehyde-3-phosphate dehydrogenase reaction of glycolysis. In turn, as a result of the first three steps of the citric acid cycle, $\alpha$-ketoglutarate, an essential precursor to biosynthesis, is obtained. However, there is no enzyme for the conversion of $\alpha$-ketoglutarate to succinate in anaerobic chemotrophs. Molecular phylogeny suggests that the citric acid cycle originated as a reductive pathway used by early autotrophs to bind $\mathrm{CO}_{2}$ at the stages of pyruvate dehydrogenase, isocitrate dehydrogenase, and $\alpha$-ketoglutarate dehydrogenase (Mathews et al. 2013; Wood et al. 2004).

\section{MACROPHAGES, THE PHAGOCYTIZING CELLS OF THE INNATE IMMUNE SYSTEM OF VERTEBRATES}

In all mammalian cells, signals provided by nutrient availability and growth factors are recognized by specific cell surface receptors (Ward \& Thompson, 2012). In cells of the immune system, the metabolic stimulation of TCR/CD28 receptors on T cells (Frauwirth et al., 2002), surface immunoglobulin receptors on B cells (Doughty et al., 2006), and Toll like receptors (TLR) on macrophages and dendritic cells (DCs) (Krawczyk et al., 2010; Haschemi et al., 2012) trigger changes in cell metabolism characteristic of the Warburg effect.

The homology of macrophages, the phagocytizing cells of the innate immune system of vertebrates, can be traced back to phagocytes of invertebrates (Hartenstein, 2006). The recognition of foreign agents in invertebrates and vertebrates occurs through pattern recognition receptors. These receptors, such as Toll-like receptors (TLR), recognize infection with fungi or Gram-positive bacteria in Drosophila and activate the Toll pathway comparably to the mammalian Toll pathway (ref. in Dzik, 2010). Although the ways of activation of TLR in Drosophila and mammals are different, the proteins of these signaling pathways are homologs to each other (Akira et al., 2006). The canonical Toll/TLR pathway can be found on the animal phylogenetic tree since the branching off the anthozoan cnidarians (Miller et al., 2007). Activation of macrophages by evolutionarily ancient Tolllike receptors or intracellular bacteria is a phenomenon that may provide a hint why the metabolic change from oxidative phosphorylation to glycolysis occurs in inflammatory macrophages.

Newsholme et al. (1986) have shown the enhancement of glycolysis accompanied by a high hexokinase activity in inflammatory mouse macrophages. The rate of glycolysis and glutamine metabolism rose significantly during phagocytosis or secretory activity. The enzymes of pentose phosphate pathway, glucose-6-phosphate dehydrogenase, and 6-phosphogluconate dehydrogenase were also very active. Resting myeloid dendritic cells (a subpopulation of monocytes/macrophages) use mainly oxidative phosphorylation to produce ATP but after stimulation of TLRs by microbial products a switch to glycolysis was observed (Krawczyk et al., 2010). This increased rate of glycolysis was accompanied by a diminution of oxidative phosphorylation and allowed to maintain a high level of ATP. The inflammatory subtype macrophages (M1) produce reactive oxygen species (ROS) and pro-inflammatory cytokines as a part of their antibacterial activity. The signals coming from the macrophage microenvironment stimulate transcriptional programs to enforce macrophage activation (Murray \& Wynn, 2011; Davies et al., 2013). Lipopolysaccharide (LPS) from the cell membrane of Gram-negative bacteria activates TLR4 what results in the activation of transcription factors such as nuclear factor $-x \mathrm{~B}(\mathrm{NF}-x \mathrm{~B})$ and interferon regulatory factors (IRFs). These factors stimulate the transcription of proinflammatory cytokines: IL-1 $\beta$, IL- 6 , and TNF- $\alpha$. These cytokines appeared in evolution in the teleost fishes (ref. in Dzik, 2010). 
In response to parasites, allergy, and long-term tissue repair macrophages present anti-inflammatory behavior (subtype M2) (Murray \& Wynn, 2011). These macrophages are very active and able to proliferate, and they rely mostly on oxidative metabolism for their energetic and biosynthetic needs. M2 macrophages produce anti-inflammatory cytokines. They are, connected with humoral immunity and are characterized by diminished expression of major histocompatibility complex (MHC) class II and hence with the low ability for the presentation of antigens (O’Neill \& Hardie, 2013). The major inducers of M2 macrophages are IL-4 and IL-13. These cytokines appeared in evolution in teleost fishes (Wang \& Secombes, 2015). The binding of IL-4, to its receptor, activates the JAK-STAT pathway. The transcription factor STAT6 is responsible for the induction of several genes including $P G C-1 \beta$ (peroxisome-proliferator-activated receptor $-\gamma$ co-activator- $1 \beta$ ) responsible for activation of oxidative metabolism (Kelly et al., 2009), Arg1 (arginase 1), Chil3 (Chitinase-like protein 3), and Retnla (Resistin-like molecule $\alpha$ or FIZZ1). Retnla represses Th2 response, induced as a result of helminth infection (Murray \& Wynn, 2011).

\section{Metabolic adaptation in activated macrophages}

Changes in macrophage metabolism are triggered by polarizing signals coming both from the surrounding milieu and pathogens. The rapid shift from a resting state to the active state of macrophages is coupled with the generation of defense factors, enhanced phagocytosis, and antigen presentation. Metabolic changes accompanying these processes in inflammatory cells resemble those in tumor cells, where mitochondrial enzymes are repurposed from the bioenergetic role of ATP generation to a biosynthetic one. However, modified metabolism in tumor cells results from mutated oncogenes and tumor suppressors (Ward \& Thompson, 2012).

In TLR4-activated macrophages, the signal from lipopolysaccharide receptor TLR4 induces a shift from the oxidative to glycolytic metabolism of the macrophages. TLR4 pathway causes induction of the glycolytic enzymes, with a change from the expression of the liver isoform of 6-Phosphofructo-2-Kinase/Fructose -2,6-Biphosphatse 1 (PFKFB1) to the 6-Phosphofructo2-Kinase/Fructose-2,6-Biphosphatase 3 (PFKFB3) isoform, the type also commonly occurring in tumor cells (Rodriguez-Prados et al., 2010). This leads to the accumulation of fructose-2,6-bisphosphate and consequently an increased glycolytic flux. In addition, pyruvate dehydrogenase kinase 1 (PDK1) inhibits the pyruvate dehydrogenase complex, decreasing the oxidation of pyruvate coming from glycolysis in TCA. PDK1 promotes glycolysis and M1 macrophage activation (Tan et al., 2015). As a result of TLR4 activation, oxidative metabolism in mitochondria is partly diminished due to nitric oxide (NO) produced in mitochondria that competitively displaces oxygen from cytochrome $c$ oxidase (West et al., 2011). This limits the activity of the electron transport chain, which causes the production of bactericidal reactive oxygen species (ROS). The activity of the pentose phosphate pathway rises because of the decreased activity of sedoheptulokinase (SHPK, CARKL) (Haschemi et al., 2012). As was mentioned earlier, NADPH produced in the pentose phosphate pathway is used for ROS removing and for the reactions producing ROS and NO, the crucial components of the antimicrobial defense $(\mathrm{Na}$ than, 1992; Babior, 1999).
Significant changes in the activity of the Krebs cycle have been identified in proinflammatory macrophages. Strongly decreased expression of isocitrate dehydrogenase caused citrate accumulation in mitochondria. Citrate can be transferred to the cytosol via CIC (citrate carrier) in exchange for cytosolic malate. It was found that mRNA and protein of CIC were markedly increased in lipopolysaccharide-activated immune cells (Infantino et al., 2011). Due to the action of ATP citrate lyase, citrate is cleaved to acetyl CoA and oxaloacetate in the cytosol. Acetyl CoA can be used for the synthesis of phospholipids, which are the source of arachidonic acid for prostaglandin production (Wightman \& Dallob, 1990). Of note, CIC gene silencing or inhibition of CIC transport activity significantly diminishes the production of $\mathrm{NO}$, ROS, and prostaglandins (Infantino et al., 2011). The second product of ATP citrate lyase, oxaloacetate, is reduced through cytosolic malate dehydrogenase to malate. The malic enzyme converts malate to pyruvate producing NADPH. Again, NADPH is required for NADPH oxidase and NO synthase. Importantly, citrate can be redirected to the generation of itaconic acid (known for its antimicrobial activity). Itaconate is a competitive inhibitor of succinate dehydrogenase (SDH) in the TCA cycle (Cordes et al., 2016). As SDH is a subunit of complex II (CII) of the electron transport chain, itaconate disturbs ETC activity that influences the regulation of mtROS production and inflammatory gene induction. Inhibition of succinate dehydrogenase causes accumulation of succinate that stabilizes the $\alpha$ subunit of HIF (hypoxia-induced factor) what allows induction of proinflammatory cytokine IL-1 $\beta$, glycolytic enzymes, and glucose transporters (Tannahill et al., 2013).

Depletion of citrate, from the TCA cycle for de novo lipid synthesis, requires restoring of the TCA cycle (termed anaplerosis) to go on. Glutamine replenishes the TCA cycle through glutaminolysis, which further results in the production of $\alpha$-ketoglutarate that enter the TCA cycle (Hensley et al., 2013). As a result of the argininosuccinate lyase activity, fumarate replenishes the cycle. The second product of this enzyme is arginine, the substrate both for arginase and nitric oxide synthase.

In the mouse peritoneal macrophages stimulated either in vivo with BCG vaccine or in vitro with (LPS + IFN- $\gamma$ ), significant enhancement of nitric oxide production takes place (Dzik et al., 2002). Jha and others (Jha et al., 2015) reported that in (LPS+IFN- $\gamma$ )-activated macrophages, aspartate, and citrulline are used by argininosuccinate synthase and argininosuccinate lyase to generate arginine, a substrate for NO production by iNOS. Mycobacterium tuberculosis infection brings about an import of arginine to macrophages to produce NO. After depletion of extracellular arginine (Qualls et al., 2012), citruline import for arginine regeneration occurs to sustain nitric oxide production.

A shift towards aerobic glycolysis takes place, aside from the LPS-activated macrophages and dendritic cells, also in M1(IFN- $\gamma$ ) inflammatory macrophages, TH17 lymphocytes producing interleukin-17, a pro-inflammatory cytokine. However, in cells that restrict inflammation, such as regulatory $\mathrm{T}$ cells, quiescent memory $\mathrm{T}$ cells that carry the CD8 antigen, and M2 anti-inflammatory macrophages, oxidative metabolism outweighs glycolysis (ref. in O’Neill \& Hardie, 2013).

M2 macrophages demonstrate augmented oxidative phosphorylation and much slower rates of glycolysis (Rodriguez-Prados et al., 2010). They express PFKFB1 but not PFKFB3. IL-4 brings about upregulation of CARKL, which preserves sedoheptulose 7-phosphate 
(S7P) levels, diminishing flow through the PPP. Expression of CARKL sensitizes macrophages to M2 polarization (Haschemi et al., 2012). IL-4 signals through STAT6

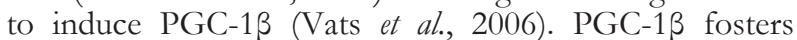
mitochondrial biogenesis and oxidative metabolism, markedly by the enhanced expression of genes, protein products of which play a role in uptake and oxidation of fatty acids (Wu et al., 2010). SIRT1 (NAD-dependent lysine deacetylase) activates PGC-1 $\beta$ (ref. in Chen et al., 2015). On the other hand, SIRT1 inactivates the p 65 component of the NF-xB (Kauppinen et al., 2013), restricting the expression of $\mathrm{NF}-x \mathrm{~B}$-dependent genes that is an anti-inflammatory action. Generation of ATP mainly from oxidative metabolism in mitochondria allows for using various sources of carbon compared with M1 macrophages. This favors M2 macrophages' role in tissue repair and anti-parasitic action. Arginase is active in both of these processes (Allen \& Wynn, 2011; Mylonas et al., 2009). It is known that STAT6 and PGC-1 $\beta$ interact directly at the promoter of the ARG1 gene and activate its transcription in M2 macrophages (Vats et al., 2006). In IL-4 activated macrophages, nitrogen from glutamine is used for the hexosamine synthesis and generation of UDP-GlcNAC. UDP-GlcNAC is the substrate for $\mathrm{N}$ glycosylation of proteins found profusely on the surface of M (IL-4) macrophages (Jha et al., 2015).

\section{Metabolic response of protozoan cells and macrophages to bacterial infection}

The metabolic programs promoting macrophage activation by inducing glycolysis or oxidative phosphorylation are used already by protozoan cells infected with bacteria. Metabolic reprogramming takes place in amoebas infected with the bacteria Legionella pneumophila, an aquatic pathogen that replicates within a wide variety of protist hosts, as well as in the vertebrate macrophages. During infection of amoeba or macrophage, the Legionella containing vesicles (LCV) are formed by endoplasmic reticulum-derived vesicles containing also mitochondria (Francione et al., 2009).

The amoeba Acanthamoeba castellanii metabolizes glucose largely via glycolysis and the pentose phosphate pathway. Pyruvate dehydrogenase transforms pyruvate into acetyl-CoA which enters the TCA cycle. As a result, the carbon backbone of many amino acids is synthesized (Schunder et al., 2014). L. pneumophila depends on amoeba's amino acids, mostly serine, from which it acquires carbon and energy for biosynthetic processes from the TCA cycle, throughout early replication (the exponential phase of growth) (Tesh et al., 1983; Price et al., 2011). L. pneumophila utilizes a conserved way of eukaryotic proteasomal degradation of Lys48-linked polyubiquitinated proteins to produce amino acids. This way is used for the growth of bacteria in amoebae as well as in human cells (Price et al., 2011). When the amino acid level turns low, the bacteria shift from the replicative phase to the transmissive phase (post-exponential growth phase) (ref. in Best et al., 2018). At this moment, the uptake and utilization of glucose by L. pneumophila increase for de novo synthesis of amino acids and storage of poly-3-hydroxybutyrate (PHB) (Häuslein et al., 2016). L. pneumophila utilizes glucose at least predominantly through the EntnerDoudoroff Pathway (Harada et al., 2010). The glycerol catabolism is also induced (Faucher et al., 2011). Thus, a switch from the replicative phase to the transmissive phase of L. pneumophila life cycle is tightly linked to the metabolism and to a life-cycle-specific substrate usage.
Several $A$. castellanii genes, products of which are involved in the oxidation of fatty acids, biosynthesis of carbohydrates, and assembly of complex III of ETC, are downregulated at eight hours after infection and remain at the same level after 24 hours post-infection (Li et al., 2020). A reduction of gene expression involved in ATP production/respiration takes place also during L. pneumophila infection of the slime mold Dictyostelium discoideum (Kjellin et al., 2019). This corresponds to a reduction of mitochondrial respiration as well as the cellular ATP pool by $6 \mathrm{~h}$ post-infection observed in macrophages (Escoll et al., 2017). The dynamics of these metabolic changes in macrophages during $L$. pneumophila infection shows that shortly after infection both glycolysis and oxidative phosphorylation are increased, which peaks one hour post-infection. Then oxidative phosphorylation is severely reduced, while glycolysis remains high. This second phase lasts at least 5 hours post-infection, which precedes bacterial replication and the beginning of the macrophage cell death. The first phase is independent of the type IV secretion system (T4SS) while the second phase is T4SS-dependent (Escoll et al., 2017). T4SS allows injecing effector proteins into macrophages in order to replicate within LCV. L. pneumophila mainly activates TLR-2 during infection (Archer et al., 2006), and activation of TLR-2 results in increased glycolysis and oxidative phosphorylation in human primary cells (Lachmandas et al., 2016). Escoll et al. (2017) suggested that increased glycolysis and increased oxidative phosphorylation in the first phase is TLR-2-dependent, but T4SS-independent. Further, they propose that bacterial effectors injected through T4SS initiate a Warburg-like program in the second phase, disrupting the mitochondrial network. Infection with $L$. pneumophila causes extended activation of NF-xB in macrophages (Fontana et al., 2011).

Induction of glycolysis and restriction of oxidative phosphorylation allow L. pneumophila to replicate due to the biosynthetic role of glycolysis (Escoll et al., 2017). Increased glycolysis and higher level of its intermediates in the infected macrophages can be used for the serine synthesis (like the pathway in proliferating cancer cells), therefore supplying the main amino acid required for the growth of L. pneumophila. Also, macrophages infected with Mycobacterium tuberculosis show an enhanced glucose uptake and increased glycolysis accompanied by diminished oxidative phosphorylation (Gleeson et al., 2016). The glycolytic intermediates are directed to lipid bodies, fatty acids from which are sources of energy and carbon (Singh et al., 2012). In the case of infection by Chlamydia trachomatis bacteria, increased glucose uptake and glycolysis were observed with flux of glycolytic intermediates to the pentose phosphate pathway to provide nucleotides for bacterial replication (Siegl et al., 2014). These examples show that host cell glycolysis seems to be the preferred metabolism for different intracellular bacteria, probably because the intermediates for bacterial growth are produced due to glycolysis. Intracellular bacteria exploit some host-cell-derived substrates as the main energy sources: Legionella uses amino acids, M. tuberculosis fatty acids, Chlamydia malate. Thus, the Warburg-like metabolism, induced in the cell by the bacterial infection, enables the synthesis of metabolites indispensable to complete the development of pathogens and their survival (Escoll et al., 2017; Gleeson et al., 2016). The Warburg-like metabolism found in phylogenetically distant protozoans and macrophages after bacterial infection shows that this strategy is evolutionarily conserved because it protects pathogens from host glucose depletion. 
Intracellularly multiplying bacteria, as well as proliferating cancer cells, have extremely large biosynthetic requirements. Only the metabolic program based on glycolysis combined with biosynthetic pathways using Krebs cycle intermediates can fulfill these demands. The aim of the program is the limitation of ATP synthesis through oxidative phosphorylation (Vander Heiden et al., 2009). Thus, the oxidative phosphorylation is relatively inactive in differentiating or proliferating cells, such as stem cells, activated T-cells, or LPS-stimulated macrophages. In these cells, metabolism relies on aerobic glycolysis (ref. in Escoll \& Buchrieser, 2018).

\section{AMPK AND TORC KEEP IN BALANCE CATABOLIC AND ANABOLIC PROCESSES}

A metabolic shift towards glycolysis was first observed in cancer cells. It takes place during embryonic development, angiogenesis, and in various organs of mature individuals. Hypoxia-induced factor $1 \alpha$ (HIF-1 $\alpha)$ and AMP-stimulated protein kinase (AMPK), are key regulators of oxygen sensing and energy balance, respectively. AMPK responds to the low energy level and it promotes cell growth inhibition and stimulation of catabolic processes to enhance nutrient availability and energy level (Hardie, 2014). An antagonist of AMPK pathway signaling is TORC (target of rapamycin complex).

Under favorable energy conditions, TORC promotes protein synthesis and cell growth (Laplante \& Sabatini, 2012). Accordingly, enzymes relevant for mitochondrial activity, glucose transport and glycolysis, carbohydrate storage, lipid metabolism, as well as protein translation and the cell cycle are controlled by AMPK and/or TOR. (Angin et al., 2016)

\section{Regulation of AMPK and TORC activity}

AMPK exists in virtually all eukaryotic cells, as a highly conserved Ser/Thr kinase. Its composition and regulation were recognized in mammalian cells. This heterotrimeric kinase consists of $\alpha, \beta$, and $\gamma$ subunits. The $\alpha$ subunit contains the catalytic domain and is the main site of enzyme regulation by phospho-dephosphorylation at threonine 172 (Thr 172) in the activation loop (Hawley et al., 1996). The $\beta$ subunit contains a carbohydratebinding module (CBM) that associates with glycogen in a phosphorylation-dependent manner (Oligschlaeger et al., 2015). The $\gamma$ subunit contains four cystathionine$\beta$-synthase (CBS) motifs; these domains create the two binding sites for AMP, the allosteric activator. The enzyme is regulated by the AMP/ATP ratio, a high ratio leading to high AMPK activity. In the most active form of the enzyme, the $\alpha$-subunit is both phosphorylated (at Thr 172) and bound to AMP at two sites. AMP regulates the AMPK activity by allosteric and covalent mechanisms (Weekes et al., 1994; Hawley et al., 1995; Davies et al., 1995) and importantly, allosterically activates upstream kinase, LKB (liver kinase B1) enhancing its activity towards AMPK. LKB1 possess high basal activity and phosphorylates Thr 172 on AMPK constitutively (Lizcano et al., 2004). In addition, binding of adenine nucleotides to the regulatory $\gamma$-subunit of AMPK brings about conformational changes that modulate the phosphorylation state of Thr 172, thus adopting the enzyme activity according to the energy status level of the cell. The binding of ATP (which indicates adequate energy levels) diminishes net Thr 172 phosphorylation, whereas binding of ADP or AMP (which indicates decreased energy levels) enhances net Thr 172 phosphorylation, increas- ing the kinase activity (Hawley et al., 1995; Oakhill et al., 2011). Finally, AMP inhibits dephosphorylation, of the AMPK by human protein phosphatase-2C $\alpha$ and native bovine protein phosphatase-2AC (Davies et al., 1995).

AMPK $\alpha$ can be phosphorylated also on Thr 172 by kinase TAK1 (transforming growth factor $\beta$-activated kinase 1) (Neumann 2018) and by CamKKs (Calmodulindependent protein kinase kinases) (Hurley et al., 2005) following the increases of intracellular $\mathrm{Ca}^{2+}$ levels. Other protein kinases PKA (Djouder et al., 2010), PKC (Heathcote et al., 2016), PKD (Coughlan et al., 2016), S6K (ribosomal subunit S6 kinase) activated by the MAPK/ ERK pathway, Akt (PKB) (Hawley et al., 2014), and glycogen synthase kinase (GSK) (Suzuki et al., 2013) phosphorylate different serine residues in the ST-loop of AMPK $\alpha$, preventing Thr 172 phosphorylation, thus inhibiting AMPK activity.

AMPK is activated under conditions of reduced generation of ATP such as glucose depletion, ischemia, oxidative stress as well as during muscle contraction (due to increase of ATP consumption) (Hardie, 2007). Due to the phosphorylation of metabolic enzymes and the effects on transcription, AMPK turns on the cellular uptake of glucose and fatty acids, and their oxidative metabolism. On the other hand, AMPK turns off biosynthetic pathways for instance the synthesis of glucose, glycogen, and lipids in the liver (ref. in Hardie et al., 2012).

AMPK activates catabolic processes and inhibits anabolic processes, partially by negative regulation of mTORC1 signaling. TOR is Ser/Thr protein kinase (Wullschleger et al., 2006; Laplante \& Sabatini, 2012) that promotes anabolic processes under conditions of high nutrient and energy levels. In mammals, there are two complexes containing mTOR kinase: mTORC1 and mTORC2. Other subunits of these complexes such as Raptor and Rictor are different from each other and are found in mTORC1 and mTORC2, respectively. mTORC1 connects the availability of nutrients (mainly amino acids) and growth factor signaling with anabolic processes in proliferating cells and tumors. Branchedchain amino acids, particularly leucine, are potent nutrient activators of mTORC1. The RAG family of small GTPases is involved in amino acid sensing (Sancak et al., 2008). AMPK phosphorylation of Raptor brings about the inhibition of mTORC1 and the arrest of cell-cycle caused by energy stress (Gwinn et al., 2008). As a result of its inhibitory effect on mTORC1 signaling, AMPK switches off protein synthesis and favors autophagy (Gwinn et al., 2008; Inoki et al., 2012). It also downregulates the expression of HIF-1 $\alpha$ (Shackelford et al., 2009).

\section{Evolutionary conservation of AMPK and TORC pathways}

AMPK is present in protists, plants, fungi, and animals (Hardie, 2014; Garcia \& Shaw, 2017). The general AMPK structure did not significantly change in the evolution of animals, except for duplications of some of the subunits. Amino acids critical for the function of AMPK are either conserved or substituted by biochemically similar residues in other taxa (ref. in Sinnett \& Brenman, 2016). These conserved amino acid residues concern those regulating AMPK activity, subunit interactions, and localization of the enzyme. A functional AMPK, as well as an LKB1 (liver kinase B1) homologs, were discovered in the amoebozoan Dictyostelium (Bokko et al., 2007, DictyBase accession no. DDB02290349; Bokko et al., 2007). In sucrose non-fermenting fungi, SNF, a homolog of AMPK was found (Hong et al., 2003). Similarly, LKB1, the upstream kinase of AMPK, is an evolutionarily con- 
served enzyme, having homologs throughout eukaryotes. Also, reaction of AMPK phosphorylation catalyzed by LKB1 is a conserved substrate-kinase reaction occurring in organisms from yeast to mammals (ref. in Nakano \& Takashima, 2012). In addition, expression of acetyl CoA carboxylase, the first enzyme of lipid biosynthesis pathway, that is phosphorylated and inactivated by AMPK (Carling et al., 1987), points to the evolutionary significance of this signaling pathway, preserved in both mammals and insects (flies) (Pan \& Hardie, 2002).

The animal AMPK enzyme regulates genes and proteins that take part in oxidative fuel selection related to the transition from energy-rich to energy-poor conditions (Hardie, 2014; Garcia \& Shaw, 2017). Once switched on, AMPK reestablishes energy homeostasis by induction of catabolic pathways that produce ATP effectively while switching off energy-using processes like biosynthesis and cell-cycle progression (Imamura et al., 2001; Jones et al., 2005). New functions were developed during the evolution of metazoans so that hormones and adipokines affect AMPK activity regulating energy balance at the whole body level (Hardie et al., 2012).

\section{Like the AMPK pathway, the TOR pathway is highly conserved from yeast to humans}

Roustan and others (Roustan et al., 2016) have reported that the phylogenetic profiles of the TOR pathway indicate the presence of both TORC1 and TORC2 already in the LUCA (last universal common ancestor). The RAG complex, which regulates TORC1 on the base of the amino acid availability is as old as the eukaryotes. The same also concerns the tuberous sclerosis complex (TSC2), which stimulates m'TORC1 (Covarrubias et al., 2015) and the pathways such as $\mathrm{I} x \mathrm{~B}$ kinase $\beta$ (IKBKB), ERK, and AK'T, which combine the extracellular and cellular energy level signals. The TORC pathway appears to be significantly stable in the course of evolution. Among several modifications, there is for instance duplication of an ancestral TSC2-like gene at the origin of the opisthokont (fungi and animals) branch, which gave rise to contemporary paralogs TSC1 and TSC2, and to the appearance of REDD1 (regulated in development and DNA damage responses 1), a hypoxia-inducible factor-1 (HIF-1) target gene, which plays a critical role in the inhibition of mTORC1 signaling during hypoxic stress (Katiyar et al., 2009). The ancestor of Opisthokontae was probably a heterotrophic organism as a common way of control of energy turnover in response to the availability of nutrients characterizes yeast and mammals. Yeast ferment glucose when it is in large quantities that is a fairly ineffective way for energy production. At that time, the expression of enzymes involved in oxidative metabolism is repressed (Gancedo, 1992). When the supply of glucose is limited, yeast SNF1 is activated (Woods et al., 1994; Wilson, et al., 1996) and the yeast cell uses other fuels suitable for a more energy-efficient oxidative metabolism. During the yeast adaptation to glucose restriction, upregulation of genes required for oxidative metabolism and downregulation of genes required for glycolysis are observed, and importantly, a SNF1 complex is necessary for most of these changes (Haurie et al., 2003).

\section{Activation of AMPK in immune cells}

The ancestral function of AMPK inferred from the role of its yeast orthologue was a response to glucose starvation, reflected by a high AMP/ATP ratio. Activation of AMPK in immune cells triggers the shift from a pro-inflammatory to an anti-inflammatory phenotype, in part by bringing a change from rapid glucose uptake and glycolysis to mitochondrial oxidative metabolism, as well as oxidation of fatty-acid (O’Neill \& Hardie, 2013). Catabolic metabolism, regulated by AMPK support the anti-inflammatory macrophage functions (O'Neill \& Pearce, 2016). Inflammatory response of bone marrowderived macrophages (BMDM) stimulated by infection with the intracellular bacteria Legionella pneumophila is accompanied by the diminished AMPK phosphorylation. This is in agreement with metabolic change observed after infection when a switch from oxidative phosphorylation to glycolysis occurs. (Escoll et al., 2017). Similarly, AMPK phosphorylation is also diminished in $L$. pneumophila-infected mouse lungs (Kajiwara et al., 2018). Anti-inflammatory cytokines, IL-10, transforming growth factor $\beta$ (TGF $\beta$ ) (ref. in Dzik, 2010), and IL-4 (Wang \& Secombes, 2015; Li et al., 2007) have appeared in evolution at the vertebrate level in the teleost fishes. The treatment of macrophages with IL-10 or TGF $\beta$ causes rapid phosphorylation, thus activation of AMPK, whereas the treatment of macrophages with LPS as a proinflammatory stimulus causes AMPK dephosphorylation and inactivation (Sag et al., 2008). AMPK prevents LPSinduced $\mathrm{I} x \mathrm{~B}-\alpha$ degradation and stimulates Akt activation. Akt inhibits glycogen synthase kinase-3 (GSK3) by its phosphorylation (Cross et al., 1995). GSK3 is the constitutively active downstream kinase of the phosphatidylinositol-3-kinase $(\mathrm{PI}(3) \mathrm{K})$. Inhibition of GSK3 causes the $\mathrm{PI}(3) \mathrm{K}$ pathway to selectively augment anti-inflammatory cytokine production with simultaneous inhibition of the pro-inflammatory cytokine production resulting from TLR stimulation of macrophages (Martin et al., 2005). Zhu and others (Zhu et al., 2015) have shown that AMPK is needed both for IL-10 activation of the PI(3) $\mathrm{K} / \mathrm{Akt} / \mathrm{mTORC1}$ pathway and STAT3-mediated antiinflammatory pathways regulating functional polarization of macrophages. The Akt-mTORC1 pathway links sensing of amino acids to IL-4 activation of macrophages, so amino acid availability rises, while amino acid insufficiency reduces the induction of IL-4-dependent genes (Covarrubias et al., 2016). Akt mediates also enhanced glucose consumption in M2 macrophages, and this contributes to induction of M2 gene expression (Covarrubias et al., 2016). Huang and others (Huang et al., 2016) have reported that mTORC2 works parallely with the IL-4R $\alpha$ /Stat 6 pathway to facilitate an enhancement of glycolysis during M2 activation via the induction of the transcription factor interferon regulatory factor 4 (IRF4). The IRF4 takes part in metabolic reprogramming to assist M2 activation and influences fatty acid oxidation. The mTORC2 pathway is clearly important for the function of M2 macrophages as its inhibition decreases immunity to the parasitic nematode Heligmosomoides polygyrus. Remarkably, AMPK may directly increase the rate of glycolysis. The enzyme is able to phosphorylate PFKFB3 enhancing its kinase activity, which results in an increase of the cellular concentrations of fructose-2,6-bisphosphate (the allosteric activator of phosphofructokinase), and the activation of glycolysis (Marsin et al., 2002). Due to this mechanism, macrophages can continue generating ATP in hypoxic regions of the infected or damaged tissue.

\section{The AMPK activation in mammalian cells by parasite infection}

Carbohydrate and lipid metabolism in macrophages is strongly affected as a result of infection with parasitic flagellates Leishmania major. mRNA levels of glucose 
transporters and key glycolytic enzymes (hexokinase, pyruvate kinase M2, and lactate dehydrogenase a are enhanced in infected cells. Also, induction of the PDK1 gene is initiated at the third hour after infection. It is accompanied by a downregulation of genes, products of which are involved in the Krebs cycle and oxidative phosphorylation. All of this suggests that in infected macrophages energy production depends mainly on the increased glycolytic flow. L. major infection induces accumulation of cholesterol and triacylglycerols as a source of high-energy substrates for the parasite needs (Rabhi et al., 2012). In addition to inflammatory mediators, L. major promastigotes also induce the transcription of genes accompanying an M2 response, such as arginase1.

The observed induction of genes encoding glycolytic enzymes in $L$. major has been confirmed by analysis of bioenergetic fluxes in Leishmania infantum-infected bone marrow-derived macrophages (BMDM) (Moreira et al., 2015). An initial transient glycolytic phase is followed by a switch to oxidative metabolism. During the glycolytic phase, a decrease of ATP/AMP and NAD/NADH ratios takes place followed by induction of the AMPK activity. SIRT1 (NAD-dependent lysine deacetylase) and LKB1/AMPK are essential for the shift to oxidative metabolism. At this point, the respiration rate and activation of peroxisome-proliferator-activated receptor- $\gamma$ co-activator-1 $\alpha$ (PGC-1 $\alpha$ ), the main inducer of mitochondrial biogenesis, increase. The energetic and redox pools of the parasite are restored. In the absence of SIRT1 or LKB1, infected macrophages cannot activate AMPK and initiate the metabolic switch. The need for macrophage AMPK for the successful Leishmania infection was demonstrated in mice with a myeloid-specific AMPK deficiency which displayed reduced parasite burden (Moreira et al., 2015). In the liver stage of malaria, Plasmodium berghei infection decreases the transcription of glycolytic enzyme phosphofructokinase 1, and in parallel increases transcription of gluconeogenesis enzymes, as well as AMPK $\alpha$ and AMPK $\gamma$ in hepatocytes (ref. in Mesquita et al., 2016). Increased glucose levels are essential for the survival of sporozoites, their metabolism is strongly dependent on glucose.

The mice lacking AMPK $\alpha 1$ in alveolar macrophages and dendritic cells presented increased Type- 1 responses, greater numbers of Th17 cells, and defects in the generation of M2 macrophages when infected with the gastrointestinal roundworm Nippostrongylus brasiliensis. Impairment of Type- 2 response was manifested by augmented intestinal worm burden. Also, tissue damages caused by the pathogen were poorly regenerated in these mice. It shows that the activity of AMPK in myeloid cells is essential for protection against gastrointestinal nematodes (Nieves et al., 2016).

\section{CELL MIGRATION}

Cell migration makes possible embryonic morphogenesis, regeneration, and repair of tissues. It also makes possible the immune response when leukocytes leave the bloodstream and migrate into the surrounding tissue to kill invading microorganisms, infected cells and to clear debris (ref. in Ridley et al., 2003). To migrate, the cell has to become polarized, i.e. the molecular processes at the front of a moving cell should be different from those in the back. The capability of a multicellular organism cell to be polarized is inherited after protists or even bacteria and is well developed in yeast to mammals (EtienneManneville, 2004). Migration of cells occurs towards a
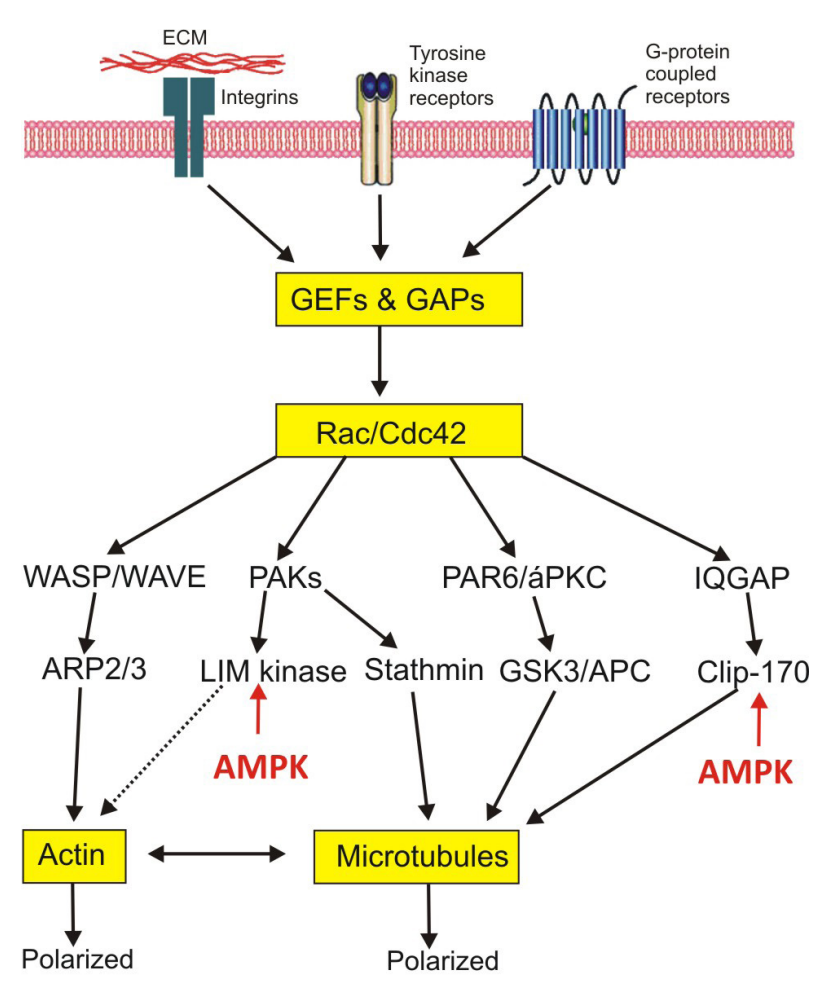

actin structures

microtubule

cytoskeleton

Figure 1. A simplified presentation of signaling pathways for cell migration with the pointing to the pathways which are influenced by AMPK (based on Etienne-Manneville, 2004).

Abbreviations: GAPs, GTPase-activating proteins; GEFs, guanine nucleotide exchange factors; Cdc42, cell division control protein 42); WASP/WAVE, Wiskott-Aldrich Syndrome protein/ WASP verprolin homologous protein; Arp2/3, actin-related proteins-2/3; APC, adenomatous polyposis coli protein; GSK3, glycogen synthase kinase-3 beta; CLIP-170, cytoplasmic linker protein 170.

gradient of the signal from growth factors, chemokines, or extracellular microenvironment (ECM) (Fig. 1). Cell surface receptors respond with the activation of $G$ proteins or receptor tyrosine kinases, stimulation of guanine nucleotide exchange factors (GEFs) for cell division control protein 42 (Cdc42) that is a small GTPase of the Rho family (which includes Rac/CDC42/RhoA), activation of phosphoinositide 3-kinases (PI3Ks), following the recruitment of activated Rac. Signaling through Rho GTPases regulate dynamics of cytoskeleton in several phases of cell migration, including polarity, adhesion, and membrane protrusions (Cain \& Ridley, 2009). The local activation of Rac and/or Cdc42, and subsequently a Wiskott-Aldrich Syndrome protein/ verprolin homologous protein (WASP/WAVE) family proteins and the actin-related proteins-2/3 ( Arp2/3) complex, trigger the arrangement of a branching actin filament network at the leading edge, which in turn brings about a protrusion in the direction of migration (ref. in Ridley et al., 2003; Fig. 1).

Cdc42/Rac signal through p21-activates kinase (PAK) that phosphorylates LIM kinase, an actin-binding kinase. PAK and LIM kinase signaling regulates actin depolymerization (Edwards et al., 1999). The interaction of Rac/ Cdc42 with PAK causes also an enhancement of the phosphorylated myosin light-chain kinase (MLCK) level 
that is essential for anchoring of lamellipodia (Kiosses et al., 1999). Cdc42 affects the location of the microtubuleorganizing center (MTOC) mainly through the PAR for "partitioning defective" (PAR6), present in a complex with PAR3 and an atypical protein kinase $\mathrm{C}$ (aPKC) (Etienne-Manneville \& Hall, 2003). This complex is suggested to orient the MTOC through local capture of microtubules at the leading edge via adenomatous polyposis coli protein (APC). It binds tubulin and locates on the ends of microtubules (Etienne-Manneville \& Hall, 2002). This interaction of APC with microtubules is diminished by phosphorylation of APC by glycogen synthase kinase-3 beta (GSK3 beta) Zumbrunn et al., 2001).

The other effector of $\mathrm{Cdc} 42 / \mathrm{Rac}$ is IQGAP. This GTPase-activating protein (GAP) is a scaffold protein containing the IQ domain (Cao et al., 2015). IQGAP1 catches the plus-ends of microtubules through cytoplasmic linker protein 170 (CLIP-170) (Gundersen, 2002).

Activated Rac1 and $\mathrm{Cdc} 42$ also tag the sites where IQGAP1 crosslinks actin filaments (not presented in Fig. 1). There, APC is acquired through IQGAP1 to actin filaments (Noritake et al., 2005). Activation of PAKs brings the phosphorylation/inhibition of the microtubule-destabilizing protein stathmin (Daub et al., 2001). According to Wittmann and others (Wittmann et al., 2003) stathmin could take part in the protrusive activity throughout cell migration.

\section{AMPK function in cell polarity and motility}

Activated AMPK increases the motility of the cell through tubulin polymerization and subsequent cytoskeletal reorganization (Nakano et al., 2010). AMPK controls cell migration by regulation of microtubule dynamics and directional cell migration through phosphorylation of the microtubule plus end protein CLIP-170 (Fig. 1). According to this, inhibition of AMPK activity prevents cell migration by hyperstabilizing the microtubule cytoskeleton via dephosphorylation of CLIP-170 (Nakano et al., 2010). AMPK has been also suggested to be involved in controlling of actin cytoskeleton dynamics and reorganization of the plasma membrane (Yan et al., 2015). An enhancement of the AMPK activity due to hypoxia suppresses migration of cells by rearranging actin filaments after phosphorylation of PDZ and LIM domain protein 5 (Pdlim5) (Fig. 1). Phosphorylation of Pdlim5 by AMPK inhibits cell migration by repressing the Rac1Arp2/3 signaling pathway. Both suppression and activation of AMPK cause inhibition of the cell migration, which suggests different mechanisms acting on CLIP170 or Pdlim5 (Yan et al., 2015).

\section{AMPK signaling in cell polarity is evolutionarily conserved}

In cultured mammalian cells, both anterior-posterior in migrating cells and apical-basal in epithelial cells polarity demands participation of the PAR-3/PAR-6/ aPKC/CDC-42 complex. In the Caenorbabditis elegans zygote (Kemphues et al., 1988), establishing of anterior- posterior cell polarity demands the expression of the PAR-3/PAR-6/aPKC/CDC-42 complex at the anterior end, but PAR1 and PAR2 at the posterior one. Although setting up the anterior- posterior axis occurs at different stages of development in response to different signals, it was found that the same conserved PAR proteins play the crucial function in the creation of polarity both in C. elegans and Drosophila melanogaster (Goldstein \& Macara, 2007).
PAR-4 is the LKB-1 orthologue in C. elegans (Narbonne \& Roy, 2006). It is indispensable for the cytoplasmic division during the early stages of embryogenesis. Maternal-effect lethal mutations in PAR-4 result in the loss of intestinal cell ability to differentiate. It has been shown that these mutations influence several facets of cell polarity (Morton et al., 1992).

In the human LS174T cell line (colon adenocarcinoma), AMPK (activated due to energy deprivation) causes complete polarization and brush border formation in cells through phosphorylation of myosin regulatory light chain (MRLC) (Lee et al., 2007). In Drosophila, AMPK controls mitotic cell division and epithelial polarity subsequent to LKB1 through direct phosphorylation of MRLC (Lee et al., 2007). Studies on HeLa cells have shown phosphorylation of AMPK during mitosis, and AMPK was restricted to components of the mitotic apparatus apparently independent of the cellular energy levels (Vazquez-Martin et al., 2009a). AMPK has been found also to regulate indirectly MRLC phosphorylation, at least in part, by phosphorylation regulatory subunit 12C (PPP1R12C) of phosphatase 1 and PAK2 in human cells during mitosis (Banko et al., 2011). For completion of mitosis phosphorylation of MRLC is necessary (Banko et al., 2011). Although energy is required to perform mitosis, the process proceeds even under energy stress in order to arrest cells at the G1/S checkpoint and allow them to await more beneficial nutrient conditions. On the other hand, the role of AMPK in mitosis may be independent of the energy status of the cell (VazquezMartin et al., 2009b). Processes such as completion of mitosis, polarization, and migration could be crucial for various physiological functions. Although AMPK activation is generally linked with reduced energy consumption, processes that need energy are also augmented by AMPK.

Phagocytic activity of neutrophils and macrophages is increased as a result of AMPK activity and ingestion of apoptotic cells or bacteria increases AMPK activity in macrophages (Bae et al., 2011). In vivo, AMPK activation results in enhanced phagocytosis of bacteria in mouse lungs.

Activation of PAK1/2 and WAVE2 (effectors of Rac1) occurs together with activation of AMPK. AMPK activation also causes phosphorylation of CLIP170 , which takes part in the synthesis of microtubules (Fig. 1). Thus, the capacity of activated AMPK to increase phagocytosis is coupled with the cytoskeleton organization, together with augmentation of microtubule and actin polymerization. According to Bae and others (Bae et al., 2011), AMPK activation concerns nonselective phagocytosis rather than more specific receptordependent mechanisms recognizing individual targets. AMPK is involved also in the regulation of phagocytosis via remodeling of the actin cytoskeleton in hemocytes of oysters (He et al., 2019).

\section{HYPOXIA-INDUCIBLE FACTOR-1 AS THE MAIN EFFECTOR TURNING ON THE ANAEROBIC METABOLISM}

Systemic and cell-autonomous adaptations have been developed in the process of evolution in response to limited oxygen availability. The crucial factors controlling metabolism under hypoxia are heterodimeric transcription hypoxia-induced factors (HIF-1 and HIF-2). Both isoforms contain $\alpha$ subunits that heterodimerize with HIF-1 $\beta$ and bind to the same DNA sequence hypoxiaresponsive element (HRE) but induced expression of 
certain genes may vary. HIF- $1 \alpha$ preferentially induces glycolytic pathway and HIF- $2 \alpha$ is involved in the regulation of genes important for tumor growth, cell cycle progression, and maintaining stem cell pluripotency (ref. in Loboda et al., 2012). HIFs activation is crucial for cell growth processes including development, angiogenesis, and vascular injury during hypoxia. The HIF-1 mediates the Pasteur effect. It is also an important mediator of the Warburg effect because of its function in the regulation of glycolysis (Seagroves et al., 2001).

HIF-1 consists of HIF- $1 \alpha$ and HIF-1 $\beta$ subunits. Both contain the helix-loop-helix-PAS (PER-ARNT-SIM) domain (Graham \& Presnell, 2017). HIF-1 $\beta$ is constitutively expressed and the expression of HIF- $1 \alpha$ is sustained at low levels in the majority of cells under normoxia.

The low level of HIF- $1 \alpha$ subunit is maintained mainly due to $\mathrm{O}_{2}$-dependent hydroxylation of proline residues: 402,564 , or both, by prolyl hydroxylase domain protein 2 (PHD2), also named EglN. The oxygen $\mathrm{Km}$ values for the hydroxylation of $\mathrm{HIF} \alpha$ by EgIN hydroxylases are just slightly over those present during normoxic conditions (Hirsila et al., 2003). Hydroxylation of each site makes a binding place for the ubiquitin ligase containing $\mathrm{PVHL}$ (von Hippel-Lindau protein), the recognition module of this enzyme that assigns HIF-1 $\alpha$ for proteasomal degradation (ref. in Semenza, 2002). These hydroxylases belong to the iron(II)- and 2-oxoglutarate-dependent dioxygenase family generating $\mathrm{CO}_{2}$ and succinate from $\mathrm{O}_{2}$ and $\alpha$-ketoglutarate. In humans, three prolyl hydroxylase isoenzymes (PHD1-3) and asparagine hydroxylase factor inhibiting HIF (FIH) have been recognized (Hewitson et al., 2003). Low concentrations of $\mathrm{O}_{2}$, high concentrations of tricarboxylic acid cycle intermediates, for instance, succinate, fumarate, also chelators of Fe(II), inhibit the activity of hydroxylases. In addition, $\mathrm{O}_{2}$-independent ubiquitination and proteasomal degradation of HIF-1 $\alpha$ take place (Liu \& Semenza, 2007).

Oxygen regulates the ability of HIF-1 $\alpha$ to activate gene transcription. Under normoxic conditions, the cooperative binding of VHL and FIH-1 allows recruiting of histone deacetylases that make the DNA less accessible to HIF-1 $\alpha$ (Mahon et al., 2001). Furthermore, oxygen-dependent hydroxylation of Asn 803 by FIH-1 disturbs the interaction of HIF-1 $\alpha$ with the co-activator p300 (Lando et al., 2002) and CREB binding protein (CBP) (Kallio et al., 1998).

Under hypoxic conditions, oxygen is rate-limiting for prolyl hydroxylase reaction (Epstein et al., 2001), which results in diminished ubiquitination of HIF-1 $\alpha$ (Sutter et al., 2000) and decreased proteasomal degradation. The HIF $\alpha$ subunit becomes stable, makes a dimer with a HIF $\beta$ subunit, translocates to the nucleus, and hundreds of genes can be activated in a cell-type-specific manner (ref. in Semenza, 2007). Hypoxia or low oxygen partial pressure cause the expression of genes involved in hematopoiesis, oxygen binding, and delivery. The HIF-1 mediated expression of genes governing energy production results in enhanced glucose uptake, and glycolysis, and diminished oxidative phosphorylation. HIF-1 directly transactivates the PDK1 gene (Kim et al., 2006; Papandreou et al., 2006). It limits the entry of pyruvate into the Krebs cycle. Instead of this, pyruvate is reduced to lactate by the lactate dehydrogenase $\mathrm{A}$ and expelled from the cell by monocarboxylate transporter 4 . Both proteins are the HIF responsive gene products (Ebert \& Bunn, 1998; Ullah et al., 2006). Inhibition of pyruvate dehydrogenase causes attenuation of mitochondrial respiration and excessive ROS generation. Lactate dehydrogenase recovers $\mathrm{NAD}^{+}$necessary to maintain glycolysis and
ATP production under hypoxia, which is critical for hypoxic cells to survive.

Synthesis of HIF-1 $\alpha$ protein depends on growth factor stimulation of receptor tyrosine kinases and a signaling pathway guiding from phosphatidylinositol-3-kinase (PI3K) to the protein kinase $\mathrm{B}$ (AKT) and FRAP/ mTOR pathway (Laughner et al., 2001). The tumor suppressor phosphatase PTEN inhibits this pathway as it dephosphorylates the products of the PI3K reaction. When the PTEN levels increase, both HIF-1 $\alpha$ expression, and HIF-1-mediated gene transcription is inhibited, as was shown to take place in the prostate cancer and glioma cells (Zhong et al., 2000; Zundel et al., 2000).

\section{Evolution of Hypoxia-inducible factor pathway}

The core elements of the HIF pathway were formed before the metazoan common ancestor and the pathway has been subjected to further processing and enlargement in each of the successor lineages (Rytkönen \& Storz, 2011). All the metazoan genomes, except for that of Bombyx mori, contain at least one HIF- $\alpha$ sequence (Graham, \& Presnell, 2017). As a result of HIF- $\alpha$ duplication in the vertebrate stem lineage, four paralogs emerged, HIF- $1 \alpha$ and HIF- $2 \alpha$ being less divergent than the small HIF- $3 \alpha$ or the HIF- $\alpha$-like ones. The two latter paralogs were lost in many vertebrate lineages. Most vertebrate genomes contain between two and six HIF- $\alpha$ genes. Although HIF- $\alpha$ homologs have been found only in metazoans, prolyl hydroxylase homologs are also found in other eukaryotes. In Caenorhabditis elegans, the mRNA levels of prolyl 4-hydroxylase (egl-9) were enhanced because of hypoxia in a HIF-1-dependent manner (Shen et al., 2005). Regulation of transcription of the prolyl 4-hydroxylase subunits by HIF turns out to be evolutionarily conserved (Takahashi et al., 2000). In humans, three PHD genes (egl-9 homologs) have been recognized, and PHD2 and PHD3 are induced by hypoxia as well. (Epstein et al., 2001; D’Angelo et al., 2003; Cioffi et al., 2003). On the other hand, homologs of FIH (factor inhibiting HIF) are not as common in metazoans as PHD enzymes.

HIF- $\beta$ subunit in invertebrates, referred to as ARNTs, is distinct from vertebrate ARNTs. Additional vertebratespecific ARNT2 is related to other vertebrate ARNT sequences. In humans, three paralogs of the HIF- $\alpha$ subunit (HIF-1 $\alpha$, HIF-2 $\alpha$ EPAS, HIF-3 $\alpha$ ) and two paralogs of the HIF- $\beta$ subunit (ARNT, ARNT2) occur (Graham \& Presnell, 2017). Over the animal kingdom HIF accumulates in hypoxic cells and operates in a very conserved way (Gorr et al., 2006). The genes strictly linked with HIF- $\alpha$ are absent in nearly all unicellular eukaryotes. This suggests that the appearance of the HIF gene family in metazoan might ensure better regulation of oxygen homeostasis corresponding with the possible higher oxygen requirements in multicellular organisms. Also, given HIF- $1 \alpha$ conservation among the majority of metazoans, the appearance of HIF-2 $\alpha$ in primitive chimaeroid fish Callorbinchus may be connected with the emergence of specialized systems for $\mathrm{O}_{2}$ delivery accompanying vascularization (Graham \& Presnell, 2017). HIF-2 $\alpha$ expression was found to be essential for erythropoiesis, vascularization, and pulmonary development in the vertebrates. The primordial role of HIF-1 is the regulation of metabolism (Semenza, 2012).

\section{Role of HIF in macrophages}

HIFs promote glycolysis and the pentose phosphate pathway inducing the relevant transporter and enzyme 
expression, to provide an adequate amount of ATP for biosynthesis and antioxidant defense in conditions of lowered mitochondrial metabolism (ref. in O'Neill \& Hardie, 2013). Stimulation of macrophages with LPS causes a switch from oxidative phosphorylation to the production of ATP by glycolysis. When mitochondria do not produce ATP, their membrane potential increases. This is combined with the altering of metabolism to channel metabolites to succinate. The inflammatory phenotype of the macrophages is governed by succinate oxidation by SDH in mitochondria (Mills et al., 2016). Enhanced oxidation of succinate and increased mitochondrial membrane potential produce a redox signal that can influence HIF-1 $\alpha$ activity (Mills et al., 2016). According to Chandel and others (Chandel et al., 2000), mitochondria-derived ROS are both required and sufficient to initiate HIF- $1 \alpha$ stabilization during hypoxia. Induction of proinflammatory IL-1 $\beta$, as well as glycolytic enzymes and glucose transporters in LPS-activated macrophages dependent on HIFs transcriptional activity (Tannahill et al., 2013). HIFs activity is enhanced also due to the upregulation of pyruvate kinase muscle (PKM2) (PalssonMcDermott et al., 2015).

Macrophages that lack HIF- $1 \alpha$ have a reduced ability to kill bacteria, and impaired production of antimicrobial peptides and granule proteases (Peyssonnaux et al., 2007; Nizet \& Johnson, 2009). HIF-1 $\alpha$ is necessary also to control the macrophage inflammatory response and promotes their phagocytic activity in the skin and joints (Cramer, 2003). Skin is a hypoxic organ and HIF-1 $\alpha$ is expressed at high levels in the skin epithelium. Peyssonnaux and others (Peyssonnaux et al., 2008) have found that the production of antimicrobial peptide cathelicidin in keratinocytes depends on HIF-1.

During inflammation, both immune cells and pathogens have enhanced metabolic demands which result in local depletion of oxygen and hypoxia (Dehne \& Brune, 2012). It was found that when monocytes differentiate under hypoxia, a distinct macrophage phenotype develops with at least partially a higher level of $\mathrm{HIF}-1 \alpha$ protein (Staples et al., 2011).

HIF-1 plays a role in the M1 polarization of macrophages (Nizet \& Johnson, 2009). It has been shown that mouse macrophages overexpressing HIF-1a represent a hyperinflammatory state, showing an enhancement of M1 markers and a diminished rate of oxygen consumption. M1 polarization of macrophages caused by HIF-1a overexpression occurred via enhanced transcription of genes connected with glycolysis. Thus, promoting glycolytic metabolism, HIF-1 induces M1 polarization of macrophages (Wang et al., 2017).

\section{Migration of macrophages and phagocytosis are HIFs- dependent processes}

Transcription factors belonging to the HIFs family also play roles in cell fate determination and cell migration (Cramer et al., 2003). In the absence of HIF$1 \alpha$, macrophages, concomitant with a decreased rate of glycolysis and energy production show impaired motility (Cramer et al., 2003). Hypoxia augments phagocytosis and bacterial killing in macrophages in a HIF-1 $\alpha$ dependent manner. HIF- $1 \alpha$ deletion in macrophages hampers the hypoxia-induced increase in phagocytosis (Anand et al., 2007).

In severe hypoxia, HIF-1 mediates induction of pyruvate dehydrogenase kinase (PDK1). As a result, inhibition of pyruvate dehydrogenase complex diminishing oxidation of pyruvate in TCA takes place. Monocyte-de- rived macrophages experience a gradual decrease in the concentration of oxygen when they migrate into areas of inflammation (Leach \& Treacher, 1998). Semba et al. (2016) have found that in mild hypoxia (4-6\% oxygen), metabolic changes mediated by HIF-1 cause induction of PDK1 even though cytochrome c oxidase activity remains unchanged, a phenomenon named by the Authors glycolytic reprogramming. In mild hypoxia, the migratory activity of macrophages (in vitro and in vivo) depends on glycolysis. Pyruvate kinase PKM2 produces ATP in the last step of glycolysis. PKM2 co-localizes with F-actin in filopodia and lamellipodia where ATP is quickly consumed during remodeling of actin (Semba et al., 2016). This suggests that even in mild hypoxia glycolytic reprogramming is essential for macrophage migration.

The myeloid-derived phagocytes neutrophils and macrophages circulating in the oxygen-reach blood have low HIFs levels. Migrating into sites of the infection, they cross the endothelium and experience decreasing concentrations of oxygen. In these conditions, prolyl hydroxylase activity is inhibited and consequently, HIF$1 \alpha$ protein is stabilized. Now, HIF- $1 \alpha$ is able to form a functional transcription factor molecule with HIF-1 $\beta$. The heterodimer translocates to the nucleus and activates transcription of innate immune response genes having hypoxia-responsive elements in their promoters. However, the maximal activation can be achieved due to the pathogen activation of TLRs and NF- $x \mathrm{~B}$, in order to increase HIF- $1 \alpha$ transcription. This transcriptional activity of HIFs results in inhibition of apoptosis, reflected in the increased lifespan of phagocytes, promotes phagocytosis, triggers the release of antimicrobial peptides and pro-inflammatory cytokines (TNF, IL-1, and IL-12), enhances TLR expression, and activates inducible NO synthase for the production of nitric oxide. Nitric oxide aside from its bactericidal activity hinders HIFs degradation, which makes an amplification loop for fast activation of phagocyte response (Nizet \& Johnson, 2009). However, the superoxide anion production by NADPH oxidase does not dependent on the transcriptional activity of HIF-1 (Peyssonnaux et al., 2005).

\section{Infection with pathogens induces HIF expression in target cells}

An acute infection caused by viruses promotes stabilization of HIFs protein in infected cells.

In the case of the common respiratory syncytial virus (RSV) infection, HIFs stabilization in human bronchial epithelial cells occurs through a NO-dependent pathway. HIFs induce VEGF production and stimulate airway edema (Kilani et al., 2004).

Stimulation of macrophages or neutrophils by a variety of bacterial species as Staphylococcus aureus, Salmonella typhimurium, and Pseudomonas aeruginosa, induces increased levels of HIFs showing that this phenomenon is characteristic of bacterial infection (ref. in Nizet \& Johnson, 2009). Such bacterial products as LPS and peptidoglycan, while activating TLRs and NF- $x \mathrm{~B}$ signaling, cause an increase of HIF-1 $\alpha$ transcription (Frede et al., 2006).

Chlamydiaceae, obligate intracellular bacteria, are able to replicate even in $3 \%$ concentration of $\mathrm{O}_{2}$ (Rupp et al., 2007). In hypoxic Human Epithelial type 2 (HEp-2) cells, Chlamydium pneumoniae causes stabilization of HIF$1 \alpha$ that promotes glucose uptake in the early phase of infection, important for replication of the bacterium. In the later phase of the chlamydial developmental cycle, uptake of glucose by C. pneumoniae-infected cells is radically decreased and further decreases subsequent to fol- 
lowing degradation of HIF- $1 \alpha$ caused by the chlamydial protease-like activity factor. Degradation of HIF-1 $\alpha$ through the mid to late phase of infection may prevent pro-apoptotic signaling in host cells helping the pathogen to persist infectious in hypoxic conditions (Rupp et al., 2007). Remarkably, HIF-1 and/or hypoxia may act either as an anti-apoptotic or pro-apoptotic factor, depending on the cell type and experimental conditions (Piret et al., 2002).

Infection with the parasitic flagellate Leishmania amazonensis results in cutaneous lesions. In the later stages of infection, induction of HIF was observed in the cytoplasm and parasitophorous vacuoles of macrophages recruited to these lesions (Arrais-Silva et al., 2005).

The obligate intracellular parasite Toxoplasma gondii causes opportunistic infections in fetuses and in immunocompromised individuals. In infected fibroblasts, expression of HIF is induced (Spear et al., 2006). HIFs subsequently activate genes for glycolytic enzymes, glucose transporters, and mevalonate metabolism (Bladder et al., 2001). Under hypoxic conditions in the brain, muscle, and retina, where the parasite causes severe pathology, both $T$. gondii replication and its organelle maintenance are severely impaired in the host cells that lack HIF$1 \alpha$. According to Spear and others (Spear et al., 2006), two alternative explanations of probable HIFs need for the parasite successful replication: a specific HIFs target gene is important for the growth of the parasite, or activity of HIFs is indispensable for the preservation of homeostasis in the infected cells. The HIF-1 function appears to be a very important mediator of cell resistance to intracellular pathogens (Knight \& Stanley, 2019).

\section{Adaptation of metazoan metabolism to changes of the oxygen concentration}

A homolog of HIF-1 is necessary for adaptation to hypoxia in the free-living nematode Caenorbabditis elegans (Jiang et al., 2001). Studies of Shen and others (Shen et al., 2005) on hypoxia-induced genes in C. elegans showed that the glycolytic enzymes: hexokinase, phosphoglucomutase, enolase, and glycerol kinase were induced in an bif-1-dependent manner. Also, aconitase and isocitrate lyase involved in the conversion of fatty acids to sugars are induced by hypoxia.

Isocitrate lyase is a part of the bifunctional malate synthase/isocitrate lyase enzyme which transforms isocitrate to glyoxylate and succinate. Malate synthase catalyzes the condensation of glyoxylate with acetyl-CoA, coming from fatty acids oxidation, giving malate, a substrate for gluconeogenesis. This bifunctional enzyme expression at high levels occurs in embryos and L1 larvae. Nematodes are the only animals in which the glyoxylate metabolism has been detected (Liu et al., 1995). Pyruvate carboxylase, the key enzyme of gluconeogenesis, producing oxaloacetate, is induced by hypoxia also, but in an bif-1-independent manner.

Parasitic nematodes adapted to the changes in oxygen concentration during their life cycle, as exemplified by free-living and parasitic forms of Ascaris summ. Its thirdstage larvae (L3) live in normoxic condition but adults live in the small intestine where the oxygen concentration is below $5 \%$. In the L3 larvae, phosphoenolpyruvate (PEP) is converted by pyruvate kinase to pyruvate in the last step of glycolysis, and acetyl-CoA is generated by pyruvate dehydrogenase complex entering the CAC. In adults living in anaerobic condition, carboxylation of PEP by phosphoenolpyruvate carboxykinase (PEPCK) is performed by the enzyme in the opposite direction than in gluconeogenesis, which results in oxaloacetate production. Oxaloacetate is reduced to malate that reaches mitochondria, where it is converted to fumarate by reversible reaction of fumarase, and fumarate is reduced to succinate (Kita \& Takamiya, 2002; Sakai et al., 2012). For fumarate reduction, complex II of ETC functions as quinol fumarate reductase (QFR, FRD), not like in aerobic conditions as succinate-ubiquinone reductase $(\mathrm{SDH}$, $\mathrm{SQR}$ ), to maintain redox balance in mitochondria of adult $A$. sum (Kita et al., 2002). Electrons from NADH are transferred to the rhodoquinone (RQ) via the NADH-RQ reductase activity of mitochondrial complex I and then to fumarate through the rhodoquinol-fumarate reductase activity of mitochondrial complex II, with the generation of succinate. This anaerobic electron transfer in complex $\mathrm{I}$ is coupled with proton transport through the inner mitochondrial membrane and allows the synthesis of ATP in anaerobic condition.

Roos \& Tielens (Roos \& Tielens, 1994) have found differences in the expression pattern of two genes coding the $\mathrm{B}$ subunit of the complex II between free-living (L3) and adult nematodes Haemonchus contortus. All adult parasitic worms examined until now use fermentative pathways for energy production. The major end products of anaerobic metabolism are typically lactate, succinate, acetate, and propionate. Remarkably, the generation of the same range of end products is favored both in the presence and in the absence of oxygen (Barrett, 1991).

Both hif- $1 a$ and bif- $1 \beta$ mRNAs are present at all stages of $A$. summ life cycle, and most profusely in the aerobic free-living L3 larvae. Then their levels slowly diminish after infection of the host (Goto et al., 2013). High levels of hif-1 mRNAs in third-stage larvae would be a preadaptation to a hypoxic environment in the small intestine. This phenomenon suggests the necessity of a rapid, adequate response resulting in the regulation of genes involved in anaerobic energy metabolism in the face of sudden changes in oxygen concentrations. It shows transcription of $A$. sum hif- 1 regulated rather at the stagespecific way than in the oxygen-dependent way (Goto et al., 2013). The genes of all subunits of mitochondrial complex II (succinate-ubiquinone reductase/quinol-fumarate reductase), are stage-specific expressed (excluding the adult-type flavoprotein subunit), and have putative hypoxia-responsive elements, which suggests that they are HIF-1 responsible genes (Goto et al., 2013).

Hypoxic conditions induce bif-1a transcription in the hypoxia-tolerant mole rat Spalax. Even in normoxia, Spalax has 2-times higher levels of bif-1a mRNA than found in the sensitive to the hypoxia rat Rattus, which enable successful responses to hypoxia (Shams et al., 2004).

These examples of bif-1 mRNAs accumulation under normoxia in the otherwise evolutionarily distant organisms imply that this way of accommodation to changes of oxygen concentrations is conserved among animals. Of note, hypoxia and body temperature interact markedly in the regulation of HIF-1 function. As was shown in a poikilothermic fish crucian carp Carassius, the activity of HIF-1 increases at low temperatures (Rytkönen et al., 2007).

Aside from parasitic invertebrates, also freshwater and marine invertebrates experience hypoxic conditions periodically in the intertidal zones. In the early phase of hypoxia, the bivalve Mytilus redox balance is sustained due to the formation of opines from pyruvate. After changing conditions to aerobic, the opines are reoxidized (Grieshaber et al., 1994). Opine formation takes place in 
the cytosol; it is a fermentation pathway in which pyruvate is condensed with arginine, alanine, or glycine by the dehydrogenase that reduces the Schiff base with NADH derived from glycolysis. As a result, iminoacid derivatives (opines) and NAD are produced. Regenerated NAD can be used for oxidative reactions. Various marine invertebrates, even the most primitive, use opine pathways (ref. in Müller et al., 2012). The amount of ATP generated by these pathways is equal to the amount produced during lactate formation, i.e. two moles of ATP per mole of glucose.

mRNAs of hif- $a$ and phd show the most intense expression in Mytilus gills. Both of them were found to be transcriptionally regulated under short-time air exposure. Also, HIF- $\alpha$ and PHD proteins were modulated in a time-dependent manner with a tendency equal to mRNA expression patterns. This suggests an essential role of HIF- $\alpha$ and PHD in the hypoxia tolerance in marine bivalves (Giannetto et al., 2015). Under prolonged anaerobiosis, malate is converted to fumarate in Mytilus, like in anaerobically living parasitic nematodes. Electrons are transported from NADH via complex I, rodoquinone, fumarate reductase to fumarate, resulting in succinate production (Tielens \& van Hellemond, 1998). Complex I pumps protons from the matrix into the intermembrane space, which allows mitochondrial ATPase to produce ATP. Succinate is either excreted as the end-product or may participate in the two mitochondrial ways providing additional ATP through substrate-level phosphorylation with two end-products, acetate or propionate (ref. in Müller et al., 2012; Zimorski et al., 2019). Succinate, acetate, and propionate together with alanine and opines are the major end products of anaerobic energy metabolism both during repression and during regular physiological activity in the majority of free-living marine invertebrates, like in parasitic nematodes (Müller et al., 2012; Zimorski et al., 2019). Aerobic and anaerobic animal lineages do not differ in terms of genes and enzymes involved in the generation of energy. Only the occurrence of rhodoquinone looks to be limited to animals that change their habitat to anaerobic.

The reduction of fumarate through the complex II under hypoxic conditions has its analog in the betaproteobacteria Rhodoferax fermentans. The complex II of $R$. fermentans and fumarate reductase located in mitochondria of facultative and anaerobic eukaryotes probably evolved independently (Miyadera et al., 2003). This is supported by the finding that the pathway for rhodoquinone biosynthesis in bacteria and some protists is different from that in Caenorbabditis elegans and parasitic helminths (Salinas et al., 2020).

Hypoxia enhances HIF- $1 \alpha$ at both mRNA and protein levels in immortalized human renal proximal tubular epithelial cells (HK-2 cells) (Chen et al., 2016). Reduction of fumarate to succinate takes place in kidney proximal tubule cells, and the resultant succinate is accumulated (Weinberg et al., 2000). Also in cancer cells, succinate, fumarate, and malate were found in greater concentrations than in healthy tissues (Hirayama et al., 2009). Lack of glucose and oxygen that imitates the tumor microenvironment, causes a decrease in the SQR activity and an increase in the FRD activity of complex II. These changes in activity are considered to be an effect of the flavoprotein subunit phosphorylation. Thus, complex II may act as a fumarate reductase in mammalian cells adapting to a hypoxic environment (Tomitsuka et al., 2009).

The unity of anaerobic energy metabolism in virtually all major lineages of eukaryotes indicates a single origin and common ancestry of the involved genes, that can be traced back to their common ancestor (Müller et al., 2012).

\section{Hematopoiesis is affected by HIFs}

Many physiological processes in developing mammalian embryos proceed in low oxygen concentrations prevailing in the uterus. Hypoxia controls the development of the placenta both through HIF-1 $\alpha$ and HIF$2 \alpha$ (Cowden et al., 2005). The likely consequence of a low oxygen concentration (between 1 and 5 percent) in the uterus (Okazaki \& Maltepe, 2006), is the stabilization of $\mathrm{HIF} \alpha$, that induces expression of $V$ egf (vascular endothelial growth factor) leading to vascular growth to provide blood and nutrients for developing tissues (ref. in Imanirad \& Dzierzak, 2013). Hematopoietic and vascular systems develop in parallel. Hypoxic hematopoietic tissues of early and mid-gestation mouse embryos show expressing HIFs and HIFs downstream targets. Both the development and function of hematopoietic progenitor/ stem cells depend on HIFs. In adults, hematopoietic stem cells are maintained in the hypoxic microenvironment that is important for regulation their quiescence. This may be a remnant feature of the hypoxic conditions, in which they were generated in the embryo (Imanirad \& Dzierzak, 2013). Genetically modified embryonic stem mouse cells (ES) show that HIF-1 $\alpha$ is required for the induction in response to hypoxia of 13 genes encoding glucose transporters and glycolytic enzymes (Iyer et al., 1998; Ryan et al., 1998).

In wild-type ES cells, lack of glucose caused induction of $V$ egf $\mathrm{mRNA}$ without induction of $\mathrm{HIF}-1 \alpha$ protein. Although under hypoxia overall protein synthesis is diminished to preserve ATP, translation of both HIF-1 $\alpha$ and VEGF, crucial for the hypoxic response, is continued due to initiation of translation by internal ribosomal entry site (ref. in Liu \& Simon, 2004)

In cancers, enhanced cellular proliferation gives rise to greater $\mathrm{O}_{2}$ use and hypoxia. Most common human cancers show overexpression of HIF-1 $1 \alpha$. To adapt to a hypoxic environment, neovascularization and increased glycolysis in solid tumors take place. HIF-1 causes an enhanced transcription of genes encoding VEGF and glycolytic enzymes as well as glucose transporters (Zhong et al., 1999). Due to the activation of HIF-1, tumor cells can produce their own energy, becoming less reliant on nutrient supply to the tumor.

\section{CONCLUSIONS}

Genes of the enzymes catalyzing reactions of glycolysis, and the citric acid cycle are present in bacteria, archaea, and eukaryotes. Metabolic pathways, producing nutrients and energy, can be traced from protozoans to mammals. Also, regulation of these pathways based on oxygen availability and energy levels has a surprisingly ancient evolutionary history and is similar both in yeast and animal cells. The metabolism specific for activated immune cells of vertebrates has the beginnings in amoeba cells infected with bacteria. Bacteria impose their metabolic demands for survival and reproduction on the host cells similarly in macrophages and amoebas. This strategy, crucial to sustaining a species, led to the preservation of these metabolic regulations in organisms phylogenetically as distant as protozoans and vertebrates (Table 1). The glucose availability influences the energy charge of the cell. Both in yeast and mammalian cells, high AMP levels reflecting low energy charge activate kinase $\mathrm{AMP}$ and its yeast orthologue (SNF1) resulting in 
Table 1. Metabolic characteristics of amoebas and macrophages after stimuli or infection with intracellular bacteria Legionella or protozoan Leishmania

\begin{tabular}{|c|c|c|c|c|c|}
\hline Cells & $\begin{array}{l}\text { M1 } \\
\text { macrophages Proin- } \\
\text { flammatory and bac- } \\
\text { tericidal, TLR-activated }\end{array}$ & $\begin{array}{l}\text { Acanthoamoeba } \\
\text { infected with } L \text {. } \\
\text { pneumophila }\end{array}$ & $\begin{array}{l}\text { Macrophages } \\
\text { infected with } L . \\
\text { pneumophila }\end{array}$ & $\begin{array}{l}\text { Macrophages infec- } \\
\text { ted with Leishmania }\end{array}$ & $\begin{array}{l}\text { M2 macrophages An- } \\
\text { tiinflammatory, tissue } \\
\text { repair and anti-parasitic }\end{array}$ \\
\hline $\begin{array}{l}\text { Hallmarks of me- } \\
\text { tabolic processes }\end{array}$ & $\begin{array}{l}\text { Glycolysis and pen- } \\
\text { tose phosphate pa- } \\
\text { thway }\end{array}$ & $\begin{array}{l}\text { Glycolysis and } \\
\text { pentose phosphate } \\
\text { pathway }\end{array}$ & $\begin{array}{l}\text { Shortly after in- } \\
\text { fection OXPHOS } \\
\text { is reduced, gly- } \\
\text { colysis remains } \\
\text { high }\end{array}$ & $\begin{array}{l}\text { Increased glycolysis. } \\
\text { Then a shift to an } \\
\text { oxidative metabo- } \\
\text { lism }\end{array}$ & OXPHOS \\
\hline $\begin{array}{l}\text { Enzymes impor- } \\
\text { tant for metabolic } \\
\text { switching }\end{array}$ & $\begin{array}{l}\text { PFKFB3 and mTORC1, } \\
\text { PDK1 }\end{array}$ & $\begin{array}{l}\text { Homologs of AMPK } \\
\text { and LKB1 found in } \\
\text { Dictyostelium model } \\
\text { organism }\end{array}$ & $\begin{array}{l}\text { Inhibition of } \\
\text { AMPK }\end{array}$ & $\begin{array}{l}\text { Induction of PDK1; } \\
\text { AMPK, SIRT1 are } \\
\text { essential for the } \\
\text { shift to OXPHOS }\end{array}$ & $\begin{array}{l}\text { PFKFB1, AMPK } \\
\text { and SIRT1 }\end{array}$ \\
\hline $\begin{array}{l}\text { Transcription } \\
\text { factors }\end{array}$ & $\begin{array}{l}\text { NF-KB and IRFs, HIF- } \\
1 \mathrm{a}\end{array}$ & $\begin{array}{l}\text { Lack of NF-KB and } \\
\text { IRFs in Protozoa** }\end{array}$ & $\begin{array}{l}\text { Prolonged acti- } \\
\text { vation of NF-KB, } \\
\text { no data for HIF-1 } \\
\text { expression }\end{array}$ & PGC-1a, HIF-1a & STAT6, PGC-1 $\beta$. \\
\hline $\begin{array}{l}\text { Metabolic de- } \\
\text { scription }\end{array}$ & $\begin{array}{l}\text { Citrate build-up, lipid } \\
\text { synthesis, ROS and } \\
\text { RNS }\end{array}$ & $\begin{array}{l}\text { Elevated levels of } \\
\text { amino acids in the } \\
\text { amoeba cytosol. } \\
\text { Down regulation of } \\
\text { genes for carbohy- } \\
\text { drate synthesis and } \\
\beta \text {-oxidation. Lack of } \\
\text { ROS in Protozoa** }\end{array}$ & $\begin{array}{l}\text { Elevated levels } \\
\text { of amino acids in } \\
\text { the macrophage } \\
\text { cytosol. Repres- } \\
\text { sion of genes for } \\
\text { protein transla- } \\
\text { tion, OXPHOS*. } \\
\text { Inhibition of ROS } \\
\text { production }\end{array}$ & $\begin{array}{l}\text { Accumulation of } \\
\text { cholesterol and tria- } \\
\text { cylglycerols for the } \\
\text { parasite growth }\end{array}$ & $\begin{array}{l}\text { Increased fatty acid oxi- } \\
\text { dation and biogenesis } \\
\text { of mitochondria, ARG1 } \\
\text { induction }\end{array}$ \\
\hline
\end{tabular}

The contents of this table is explained in the text, with addition: *Price \& Abu Kwaik (2014); **ef. in Dzik (2010). Abbreviations: AMPK, AMPstimulated protein kinase; ARG, arginase; HIF, hypoxia- induced factor; IRF, interferon responsible factor; LKB, liver kinase B; NF-KB, nuclear factor KB; OXPHOS, oxidative phosphorylation; PDK, pyruvate dehydrogenase kinase; PFKFB, 6-phosphofructo-2-kinase/fructose-2;6-biphosphatase; PGC - peroxisome-proliferator-activated receptor- $\gamma$ co-activator; ROS, reactive oxygen species; RNS, reactive nitrogen species; SIRT1, NAD-dependent lysine deacetylase; STAT — signal transducer and activator of transcription; TLR, Toll-like receptor; TORC, target of rapamycin complex.

inhibition of anabolic processes. In macrophages, catabolic processes enhanced by AMPK activity support anti-inflammatory functions. The transcription factor HIF induces a set of genes that activate anabolic processes. It promotes glycolysis, biosynthesis, and antioxidant defense against pathogens in inflammatory macrophages. Because AMPK and HIF-1 are regulated by glucose levels and oxygen concentrations respectively, they are indispensable to fundamental processes such as cell migration, or embryogenesis occurring in all multicellular eukaryotes.

\section{Acknowledgements}

I am very grateful to Elżbieta Wałajtys-Rode (Warsaw University of Technology, Faculty of Chemistry) for constructive criticism and many helpful suggestions how to improve the manuscript in respect to its merits, and Małgorzata Kloc (Research Institute Houston Methodist Weill Cornell Medical College) for critical reading and improving the manuscript.

\section{REFERENCES}

Akira S, Uematsu S, Takeuchi O (2006) Pathogen recognition and innate immunity. Cell 124: 783-801. https://doi.org/10.1016/j. cell.2006.02.015

Allen JE, Wynn TA (2011) Evolution of Th2 immunity: a rapid repair response to tissue destructive pathogens. PLoS Pathog 7: e1002003. https://doi.org/10.1371/journal.ppat.1002003

Amoêdo ND, Valencia JP, Rodrigues MF, Galina A, Rumjanek FD (2013) How does the metabolism of tumour cells differ from that of normal cells. Biosci Rep 33: e00080. https://doi.org/10.1042/ BSR20130066

Anand RJ, Gribar SC, Li J, Kohler JW, Branca MF, Dubowski T, Sodhi CP, Hackam DJ (2007) Hypoxia causes an increase in phagocytosis by macrophages in a HIF-1alpha-dependent manner. I Leukoc Biol 82: 1257-1265. https://doi.org/10.1189/jlb.0307195
Angin Y, Beauloye C, Horman S, Bertrand L (2016) Regulation of carbohydrate metabolism, lipid metabolism, and protein metabolism by AMPK. Exp Suppl 107: 23-43. https://doi.org/10.1007/978-3-31943589-3 2. PMID: 27812975

Archer KA, Roy CR (2006) MyD88-dependent responses involving toll-like receptor 2 are important for protection and clearance of $L e$ gionella pneumophila in a mouse model of Legionnaires' disease. Infect Immun 74: 3325-3333. https://doi.org/10.1128/IAI.02049-05

Arrais-Silva WW, Paffaro VA Jr, Yamada AT, Giorgio S (2005) Expression of hypoxia-inducible factor-1alpha in the cutaneous lesions of BALB/c mice infected with Leishmania amazonensis. Exp Mol Pathol 78: 49-54. https://doi.org/10.1016/j.yexmp.2004.09.002

Babior BM (1999) NADPH Oxidase: An update. Blood 93: 1464-1476

Bae HB, Zmijewski JW, Deshane JS, Tadie JM, Chaplin DD, Takashima S, Abraham E (2011) AMP-activated protein kinase enhances the phagocytic ability of macrophages and neutrophils. FASEB J 25: 4358-4368. https://doi.org/10.1096/fj.11-190587

Banko MR, Allen JJ, Schaffer BE, Wilker EW, Tsou P, White JL, Villén J, Wang B, Kim SR, Sakamoto K, Gygi SP, Cantley LC, Yaffe MB, Shokat KM, Brunet A (2011) Chemical genetic screen for $A M P K \alpha 2$ substrates uncovers a network of proteins involved in mitosis. Mol Cell 44: 878-892. https://doi.org/10.1016/j.molcel.2011.11.005

Barrett J (1991) Parasitic helminths, In Metazoan life without oxygen Bryant C. ed, pp 146-164. Chapman and Hall, London

Best A, Price C, Ozanic M, Santic M, Jones S, Abu Kwaik Y (2018) A Legionella pneumophila amylase is essential for intracellular replication in human macrophages and amoebae. Sci Rep 8: 6340. https://doi. org/10.1038/s41598-018-24724-1

Blader IJ, Manger ID, Boothroyd JC (2001) Microarray analysis reveals previously unknown changes in Toxoplasma gondii-infected human cells. J Biol Chem 276: 24223-24231. https://doi.org/10.1074/jbc. M100951200

Bokko PB, Francione L, Bandala-Sanchez E, Ahmed AU, Annesley SJ, Huang X, Khurana T, Kimmel AR, Fisher PR (2007) Diverse cytopathologies in mitochondrial disease are caused by AMP-activated protein kinase signaling. Mol Biol Cell 18: 1874-1886. https://doi. org/10.1091/mbc.e06-09-0881

Bräsen C, Esser D, Rauch B, Siebers B (2014) Carbohydrate metabolism in Archaea: current insights into unusual enzymes and pathways and their regulation. Microbiol Mol Biol Rev 78: 89-175. https:// doi.org/10.1128/MMBR.00041-13

Broeckx T, Hulsmans S, Rolland F (2016) The plant energy sensor: evolutionary conservation and divergence of SnRK1 structure, 
regulation, and function. I Exp Bot 67: 6215-6252. https://doi. org/10.1093/jxb/erw416

Cain RJ, Ridley AJ (2009) Phosphoinositide 3-kinases in cell migration. Biol Cell 101: 13-29. https://doi.org/10.1042/BC20080079

Cao D, Su Z, Wang W, Wu H, Liu X, Akram S, Qin B, Zhou J, Zhuang X, Adams G, Jin C, Wang X, Liu L, Hill DL, Wang D, Ding X, Yao X (2015) Signaling scaffold protein IQGAP1 interacts with microtubule plus-end tracking protein SKAP and links dynamic microtubule plus-end to steer cell migration. J Biol Chem 290: 23766-23780. https://doi.org/10.1074/jbc.M115.673517

Carling D, Zammit VA, Hardie DG (1987) A common bicyclic protein kinase cascade inactivates the regulatory enzymes of fatty acid and cholesterol biosynthesis. FEBS Lett 223: 217-222. https://doi. org/10.1016/0014-5793(87)80292-2

Chandel NS, Maltepe E, Goldwasser E, Mathieu CE, Simon MC and Schumacker PT (1998) Mitochondrial reactive oxygen species trigger hypoxia-induced transcription. Proc Natl Acad Sci USA 95: 1171511720. https://doi.org/10.1073/pnas.95.20.11715

Chandel NS, McClintock DS, Feliciano CE, Wood TM, Melendez JA, Rodriguez AM, Schumacker PT (2000) Reactive oxygen species generated at mitochondrial complex III stabilize hypoxia-inducible factor-1alpha during hypoxia: a mechanism of $\mathrm{O} 2$ sensing. I Biol Chem 275: 25130-25138. https://doi.org/10.1074/jbc.M001914200

Chen X, Lu Y, Zhang Z, Wang J, Yang H, Liu G (2015) Intercellular interplay between Sirt1 signalling and cell metabolism in immune cell biology. Immunology 145: 455-467. https://doi.org/10.1111/ imm.12473

Chen Y, Jiang S, Zou J, Zhong Y, Ding X (2016) Silencing HIF-1 $\alpha$ aggravates growth inhibition and necrosis of proximal renal tubular epithelial cell under hypoxia. Ren Fail. 38: 1726-1734. https://doi.or g/10.1080/0886022X.2016.1229994

Cioffi CL, Liu XQ, Kosinski PA, Garay M, Bowen BR (2003) Differential regulation of HIF- 1 alpha prolyl-4-hydroxylase genes by hypoxia in human cardiovascular cells. Biochem Biophys Res Commun 303: 947-953. https://doi.org/10.1016/s0006-291x(03)00453-4

Corcoran SE, O’Neill LA (2016) HIF1 $\alpha$ and metabolic reprogramming in inflammation. J Clin Invest 126: 3699-3707. https://doi. org/10.1172/JCI84431

Cordes T, Wallace M, Michelucci A, Divakaruni AS, Sapcariu SC, Sousa C, Koseki H, Cabrales P, Murphy AN, Hiller K, Metallo CM (2016) Immunoresponsive gene 1 and itaconate inhibit succinate dehydrogenase to modulate intracellular succinate levels. I Biol Chem 2911: 4274-4284. https://doi.org/10.1074/jbc.M115.685792

Coughlan KA, Valentine RJ, Sudit BS, Allen K, Dagon Y, Kahn BB, Ruderman NB, Saha AK (2016) PKD1 Inhibits AMPK $\alpha 2$ through phosphorylation of serine 491 and impairs insulin signaling in skeletal muscle cells. J Biol Chem 291: 5664-5675. https://doi. org/10.1074/jbc.M115.696849

Covarrubias AJ, Aksoylar HI, Horng T (2015) Control of macrophage metabolism and activation by mTOR and Akt signaling. Semin Immunol 27: 286-296. https://doi.org/10.1016/j.smim.2015.08.001. https://doi.org/10.1016/j.smim.2015.08.001

Covarrubias AJ, Aksoylar HI, Yu J, Snyder NW, Worth AJ, Iyer SS, Wang J, Ben-Sahra I, Byles V, Polynne-Stapornkul T, Espinosa EC, Lamming D, Manning BD, Zhang Y, Blair IA, Horng T (2016) Akt mTORC1signaling regulates Acly to integrate metabolic input to control of macrophage activation. Elife 5: e11612. https://doi. org/10.7554/eLife.11612.001

Cowden Dahl KD, Fryer BH, Mack FA, Compernolle V, Maltepe E, Adelman DM, Carmeliet P, Simon MC (2005) Hypoxia-inducible factors 1 alpha and 2alpha regulate trophoblast differentiation. Mol Cell Biol 25: 10479-10491. https://doi.org/10.1128/MCB.25.23

Cramer T, Yamanishi Y, Clausen BE, Förster I, Pawlinski R, Mackman N, Haase VH, Jaenisch R, Corr M, Nizet V, Firestein GS, Gerber HP, Ferrara N, Johnson RS (2003) HIF-1alpha is essential for myeloid cell-mediated inflammation. Cell 112: 645-657. https://doi. org/10.1016/s0092-8674(03)00154-5

Cross DAE, Alessi DR, Cohen P, Andjelkovich M. Hemmings BA (1995) Inhibition of glycogen synthase kinase- 3 by insulin mediated by protein kinase B. Nature 378: 785-789. https://doi.org/ org/10.1038/378785a0

Dagon Y, Hur E, Zheng B, Wellenstein K, Cantley LC, Kahn BB (2012) p70S6 kinase phosphorylates AMPK on serine 491 to mediate leptin's effect on food intake. Cell Metab 16: 104-112. https:// doi.org/10.1016/j.cmet.2012.05.010

D’Angelo G, Duplan E, Boyer N, Vigne P, Frelin C (2003) Hypoxia up-regulates prolyl hydroxylase activity: a feedback mechanism that limits HIF-1 responses during reoxygenation. J Biol Chem 278: 38183-38187. https://doi.org/10.1074/jbc.M302244200

Daub H, Gevaert K, Vandekerckhove J, Sobel A, Hall A (2001) Rac/ Cdc42 and p65PAK regulate the microtubule-destabilizing protein stathmin through phosphorylation at serine 16. J Biol Chem 276: 1677-1680. https://doi.org/10.1074/jbc.C000635200

Davies LC, Jenkins SJ, Allen JE, Taylor PR (2013) Tissue-resident macrophages. Nat Immunol 14: 986-995. https://doi.org/10.1038/ ni. 2705
Davies SP, Helps NR, Cohen PT, Hardie DG (1995) 5'-AMP inhibits dephosphorylation, as well as promoting phosphorylation, of the AMP-activated protein kinase. Studies using bacterially expressed human protein phosphatase- $2 \mathrm{C}$ alpha and native bovine protein phosphatase-2AC. FEBS Lett 377: 421-425. https://doi. org/10.1016/0014-5793(95)01368-7

Dehne N, Brüne B (2014) Sensors, transmitters, and targets in mitochondrial oxygen shortage - A hypoxia-inducible factor relay story. Antioxid Redox Signal 20: 339-352. https://doi.org/10.1089/ ars.2012.4776

Djouder N, Tuerk RD, Suter M, Salvioni P, Thali RF, Scholz R, Vaahtomeri K, Auchli Y, Rechsteiner H, Brunisholz RA, Viollet B, Mäkelä TP, Wallimann T, Neumann D, Krek W (2010) PKA phosphorylates and inactivates AMPK alpha to promote efficient lipolysis. EMBO J 29: 469-481. https://doi.org/10.1038/emboj.2009.339

Doughty CA, Bleiman BF, Wagner DJ, Dufort FJ, Mataraza JM, Roberts MF, Chiles TC (2006) Antigen receptor-mediated changes in glucose metabolism in B lymphocytes: role of phosphatidylinositol 3-kinase signaling in the glycolytic control of growth. Blood 107: 4458-4465. https://doi.org/10.1182/blood-2005-12-4788

Dzik JM (2010) The ancestry and cumulative evolution of immune reactions. Acta Biochim Polon 57: 443-466

Dzik JM (2014) Evolutionary roots of arginase expression and regulation. Front Immunol 5: 544. https://doi.org/10.3389/fimmu.2014.00544

Dzik JM, Gołos B, Jagielska E, Zieliński Z, Wałajtys-Rode E (2004) A non-classical type of alveolar macrophage response to Trichinella spiralis infection. Parasite Immunol 26: 197-205. https://doi. org/10.1111/j.0141-9838.2004.00700.x

Ebert BL, Bunn HF (1998) Regulation of transcription by hypoxia requires a multiprotein complex that includes hypoxia-inducible factor 1 , an adjacent transcription factor, and p300/CREB binding protein. Mol Cell Biol 18: 4089-4096. https://doi.org/10.1128/mcb.18.7.4089

Edwards DC, Sanders LC, Bokoch GM, Gill GN (1999) Activation of LIM-kinase by Pak1 couples Rac/Cdc42 GTPase signalling to actin cytoskeletal dynamics. Nat Cell Biol 1: 253-259. https://doi. org/10.1038/12963

Eisenreich W, Rudel T, Heesemann J, Goebel W (2017) To eat and to be eaten: mutual metabolic adaptations of immune cells and intracellular bacterial pathogens upon infection. Front Cell Infect Microbiol 7: 316. https://doi.org/10.3389/fcimb.2017.00316

Epstein AC, Gleadle JM, McNeill LA, Hewitson KS, O’Rourke J, Mole DR, Mukherji M, Metzen E, Wilson MI, Dhanda A, Tian YM, Masson N, Hamilton DL, Jaakkola P, Barstead R, Hodgkin J, Maxwell PH, Pugh CW, Schofield CJ, Ratcliffe PJ (2001) C. elegans EGL9 and mammalian homologs define a family of dioxygenases that regulate HIF by prolyl hydroxylation. Cell 107: 43-54. https://doi. org/10.1016/s0092-8674(01)00507-4

Escoll P, Buchrieser C (2018) Metabolic reprogramming of host cells upon bacterial infection: Why shift to a Warburg-like metabolism? FEBS J 12: 2146-2160. https://doi.org/10.1111/febs.14446

Escoll P, Song OR, Viana F, Steiner B, Lagache T, Olivo-Marin JC, Impens F, Brodin P, Hilbi H \& Buchrieser C (2017) Legionella pneumophila modulates mitochondrial dynamics to trigger metabolic repurposing of infected macrophages. Cell Host Microbe 22: 302-316. e7. https://doi.org/10.1016/j.chom.2017.07.020

Etienne-Manneville S, Hall A (2002) Rho GTPases in cell biology. Nature 420: 629-635. https://doi.org/10.1038/nature01148

Etienne-Manneville S, Hall A (2003) Cell polarity: Par6, aPKC and cytoskeletal crosstalk. Curr Opin Cell Biol 15: 67-72. https://doi. org/10.1016/s0955-0674(02)00005-4

Faucher SP, Mueller CA, Shuman HA (2011) Legionella pneumophila Transcriptome during intracellular multiplication in human macrophages. Front Microbiol 2: 60. https://doi.org/10.3389/ fmicb.2011.00060

Fontana MF, Banga S, Barry KC, Shen X, Tan Y, Luo ZQ, Vance RE (2011) Secreted bacterial effectors that inhibit host protein synthesis are critical for induction of the innate immune response to virulent Legionella pneumophila. PLoS Pathog 7: e1001289. https://doi. org/10.1371/journal.ppat.1001289

Fossett N, Tevosian SG, Gajewski K, Zhang Q, Orkin SH, Schulz RA (2001) The Friend of GATA proteins U-shaped, FOG-1, and FOG-2 function as negative regulators of blood, heart, and eye development in Drosophila. Proc Natl Acad Sci USA 98: 7342-7347. https://doi.org/10.1073/pnas.131215798

Francione L, Smith PK, Accari SL, Taylor PE, Bokko PB, Bozzaro S, Beech PL, Fisher PR (2009) Legionella pneumophila multiplication is enhanced by chronic AMPK signalling in mitochondrially diseased Dictyostelium cells. Dis Model Mech 2: 479-489. https://doi. org/10.1242/dmm.003319

Frauwirth KA, Riley JL, Harris MH, Parry RV, Rathmell, JC, Plas DR, Elstrom RL, June CH, Thompson CB (2002) The CD28 signaling pathway regulates glucose metabolism. Immunity 16: 769-777. https://doi.org/org/10.1016/s1074-7613(02)00323-0

Frede S, Stockmann C, Freitag P, Fandrey J (2006) Bacterial lipopolysaccharide induces HIF-1 activation in human monocytes via 
p44/42 MAPK and NF-kappaB. Biochem J 396: 517- 527. https:// doi.org/10.1042/BJ20051839

Fuhrmann DC, Wittig I, Heide H, Dehne N, Brüne B (2013) Chronic hypoxia alters mitochondrial composition in human macrophages. Biochim Biophys Acta 1834: 2750-2760. https://doi.org/10.1016/j. bbapap.2013.09.023

Gancedo JM (1992) Carbon catabolite repression in yeast. Eur J Biochem 206: 297-313. https://doi.org/10.1111/j.1432-1033.1992.tb16928.x

Garcia D, Shaw RJ (2017) AMPK: mechanisms of cellular energy sensing and restoration of metabolic balance. Mol. Cell 66: 789-800. https://doi.org/org/10.1016/i.molcel.2017.05.032

Giannetto A, Maisano M, Cappello T, Oliva S, Parrino V, Natalotto A, De Marco G, Barberi C, Romeo O, Mauceri A, Fasulo S (2015) Hypoxia-inducible factor $\alpha$ and Hif-prolyl hydroxylase characterization and gene expression in short-time air-exposed Mytilus galloprovincialis. Mar Biotechnol (NY) 17: 768-781. https://doi.org/10.1007/ s10126-015-9655-7

Gleeson LE, Sheedy FJ, Palsson-McDermott EM, Triglia D, O'Leary SM, O’Sullivan MP, O’Neill LAJ, Keane J (2016) Cutting edge: $M y$ cobacterium tuberculosis induces aerobic glycolysis in human alveolar macrophages that is required for control of intracellular bacillary replication. J Immunol 196: 2444-2449. https://doi.org/10.4049/jimmunol.1501612

Gold KS, Brückner K (2014) Drosophila as a model for the two myeloid blood cell systems in vertebrates. Exp Hematol 42: 717-727. https://doi.org/10.1016/j.exphem.2014.06.002

Goldstein B, Macara IG (2007) The PAR proteins: fundamental players in animal cell polarization. Dev Cell 13: 609-622. https://doi. org/10.1016/j.devcel.2007.10.007

Gorr TA, Gassmann M, Wappner P (2006) Sensing and responding to hypoxia via HIF in model invertebrates. J Insect Physiol 52: 349-364. https://doi.org/10.1016/j.jinsphys.2006.01.002

Goto M, Amino H, Nakajima M, Tsuji N, Sakamoto K, Kita K (2013) Cloning and characterization of hypoxia-inducible factor-1 subunits from Ascaris suum - a parasitic nematode highly adapted to changes of oxygen conditions during its life cycle. Gene 516: 39-47. https:// doi.org/10.1016/j.gene.2012.12.025

Graham AM, Presnell JS (2017) Hypoxia Inducible Factor (HIF) transcription factor family expansion, diversification, divergence and selection in eukaryotes. PLoS One 12: e0179545. https://doi. org/10.1371/journal.pone.0179545

Grieshaber MK, Hardewig I, Kreutzer U, Pörtner HO (1994) Physiological and metabolic responses to hypoxia in invertebrates. Rev Physiol Biochem Pharmacol 25: 43-147. https://doi.org/10.1007/ BFb0030909

Gundersen GG (2002) Microtubule capture: IQGAP and CLIP170 expand the repertoire. Curr Biol 12: R645-R647. https://doi. org/10.1016/s0960-9822(02)01156-9

Gwinn DM, Shackelford DB, Egan DF, Mihaylova MM, Mery A, Vasquez DS, Turk BE, Shaw RJ (2008) AMPK phosphorylation of raptor mediates a metabolic checkpoint. Mol Cell 30: 214-226. https://doi.org/10.1016/j.molcel.2008.03.003

Harada E, Iida K, Shiota S, Nakayama H, Yoshida S (2010) Glucose metabolism in Legionella pneumophila: dependence on the Entner-Doudoroff pathway and connection with intracellular bacterial growth. J Bacteriol 192: 2892-2899. https://doi.org/10.1128/ JB.01535-09

Hardie DG (2007)AMP-activated/SNF1 protein kinases: conserved guardians of cellular energy. Nat Rev Mol Cell Biol 8: 774-785. https://doi.org/10.1038/nrm2249

Hardie DG (2014) AMPK-sensing energy while talking to other signaling pathways. Cell Metab 20: 939-952. https://doi.org/10.1016/j. cmet.2014.09.013

Hardie DG, Ross FA, Hawley SA (2012) AMP-activated protein kinase: a target for drugs both ancient and modern. Chem Biol 19: 1222-1236. https://doi.org/10.1016/j.chembiol.2012.08.019

Hardie DG, Scott JW, Pan DA, Hudson ER (2003) Management of cellular energy by the AMP-activated protein kinase system. FEBS Lett 546: 113-120. https://doi.org/10.1016/s0014-5793(03)00560-x

Hartenstein V (2006) Blood cells and blood cell development in the animal kingdom. Annu Rev Cell Dev Biol 22: 677-712. https://doi. org/10.1146/annurev.cellbio.22.010605.093317

Haschemi A, Kosma P, Gille L, Evans CR, Burant CF, Starkl P, Knapp B, Haas R, Schmid JA, Jandl C, Amir S, Lubec G, Park J, Esterbauer H, Bilban M, Brizuela L, Pospisilik JA, Otterbein LE, Wagner O (2012) The sedoheptulose kinase CARKL directs macrophage polarization through control of glucose metabolism. Cell Metab 15: 813-826. https://doi.org/10.1016/j.cmet.2012.04.023

Haschemi A, Kosma P, Gille L, Evans CR, Burant CF, Starkl P, Knapp B, Haas R, Schmid JA, Jandl C, Amir S, Lubec G, Park J, Esterbauer H, Bilban M, Brizuela L, Pospisilik JA, Otterbein LE, Wagner O (2012) The sedoheptulose kinase CARKL directs macrophage polarization through control of glucose metabolism. Cell Metab 15: 813-826. https://doi.org/10.1016/j.cmet.2012.04.023

Hattori K, Heissig B, Wu Y, Dias S, Tejada R, Ferris B, Hicklin DJ, Zhu Z, Bohlen P, Witte L, Hendrikx J, Hackett NR, Crystal RG,
Moore MA, Werb Z, Lyden D, Rafii S (2002) Placental growth factor reconstitutes hematopoiesis by recruiting VEGFR1 $\left(^{+}\right)$stem cells from bone-marrow microenvironment. Nat Med 8: 841-849. https://doi.org/10.1038/nm740

Haurie V, Boucherie H, Sagliocco F (2003) The Snf1 protein kinase controls the induction of genes of the iron uptake pathway at the diauxic shift in Saccharomyces cerevisiae. I Biol Chem 278: 45391-45396. https://doi.org/10.1074/jbc.M307447200

Häuslein I, Manske C, Goebel W, Eisenreich W, Hilbi H (2016) Pathway analysis using (13)C-glycerol and other carbon tracers reveals a bipartite metabolism of Legionella pneumophila. Mol Microbiol 100: 229-246. https://doi.org/10.1111/mmi.13313

Hawley SA, Davison M, Woods A, Davies SP, Beri RK, Carling D, Hardie DG (1996) Characterization of the AMP-activated protein kinase kinase from rat liver and identification of threonine 172 as the major site at which it phosphorylates AMP-activated protein kinase. J Biol Chem 271: 27879-27887. https://doi.org/10.1074/ jbc.271.44.27879

Hawley SA, Ross FA, Gowans GJ, Tibarewal P, Leslie NR, Hardie DG (2014) Phosphorylation by Akt within the ST loop of AMPK- $\alpha 1$ down-regulates its activation in tumour cells. Biochem J 459: 275287. https://doi.org/10.1042/BJ20131344

Hawley SA, Selbert MA, Goldstein EG, Edelman AM, Carling D, Hardie DG (1995) 5'-AMP activates the AMP-activated protein kinase cascade, and $\mathrm{Ca}^{2+} /$ calmodulin activates the calmodulin-dependent protein kinase I cascade, via three independent mechanisms. J Biol Chem 270: 27186-27191. https://doi.org/10.1074/jbc.270.45.27186

He Z, Mao F, Lin Y, Li J, Zhang X, Zhang Y, Xiang Z, Noor Z, Zhang Y, Yu Z (2019) Molecular characteristics of AMPK and its role in regulating the phagocytosis of oyster hemocytes. Fish Shellfish Immunol 93: 416-427. https://doi.org/10.1016/j.fsi.2019.07.075

Heathcote HR, Mancini SJ, Strembitska A, Jamal K, Reihill JA, Palmer TM, Gould GW, Salt IP (2016) Protein kinase C phosphorylates AMP-activated protein kinase $\alpha 1$ Ser487. Biochem J 473: 4681-4697. https://doi.org/10.1042/BCJ20160211

Hensley CT, Wasti AT, DeBerardinis RJ (2013) Glutamine and cancer: cell biology, physiology, and clinical opportunities. J Clin Invest 123: 3678-3684. https://doi.org/10.1172/JCI69600

Hewitson KS, McNeill LA, Elkins JM, Schofield CJ (2003) The Role of iron and 2-oxoglutarate oxygenases in signalling. Biochem Soc Trans 31: 510-515. https://doi.org/10.1042/bst0310510

Hirayama A, Kami K, Sugimoto M, Sugawara M, Toki N, Onozuka H, Kinoshita T, Saito N, Ochiai A, Tomita M, Esumi H, Soga T (2009) Quantitative metabolome profiling of colon and stomach cancer microenvironment by capillary electrophoresis time-offlight mass spectrometry. Cancer Res 69: 4918-4925. https://doi. org/10.1158/0008-5472

Hirsilä M, Koivunen P, Günzler V, Kivirikko KI, Myllyharju J (2003) Characterization of the human prolyl 4-hydroxylases that modify the hypoxia-inducible factor. J Biol Chem 278: 30772-30780. https://doi. org/10.1074/jbc.M304982200

Hong SP, Leiper FC, Woods A, Carling D, Carlson M (2003) Activation of yeast Snf1 and mammalian AMP-activated protein kinase by upstream kinases. Proc Natl Acad Sci USA 100: 8839-8843. https:// doi.org/10.1073/pnas.1533136100

Huang SC, Smith AM, Everts B, Colonna M, Pearce EL, Schilling JD, Pearce EJ (2016) Metabolic reprogramming mediated by the mTORC2-IRF4 signaling axis is essential for macrophage alternative activation. Immunity 45: 817-830. https://doi.org/10.1016/j.immuni.2016.09.016

Hurley RL, Anderson KA, Franzone JM, Kemp BE, Means AR, Witters LA (2005) The $\mathrm{Ca}^{2+} /$ calmodulin-dependent protein kinase kinases are AMP-activated protein kinase kinases. I Biol Chem 280: 29060-29066. https://doi.org/10.1074/jbc.M503824200

Imamura K, Ogura T, Kishimoto A, Kaminishi M, Esumi H (2001) Cell cycle regulation via 53 phosphorylation by a 5'-AMP activated protein kinase activator, 5-aminoimidazole-4-carboxamide-1-betaD-ribofuranoside, in a human hepatocellular carcinoma cell line. Biochem Biophys Res Commun 287: 562-567. https://doi.org/10.1006/ bbrc. 2001.5627

Imanirad P, Dzierzak E (2013) Hypoxia and HIFs in regulating the development of the hematopoietic system. Blood Cells Mol Dis 51: 256-263. https://doi.org/10.1016/j.bcmd.2013.08.005

Infantino V, Convertini P, Cucci L, Panaro MA, Di Noia MA, Calvello R, Palmieri F, Iacobazzi V (2011) The mitochondrial citrate carrier: a new player in inflammation Biochem J 438: 433-436. https://doi. org/0.1042/BJ20111275

Inoki K, Kim J, Guan KL (2012) AMPK and mTOR in cellular energy homeostasis and drug targets. Annu Rev Pharmacol Toxicol 52: 381400. https://doi.org/10.1146/annurev-pharmtox-010611-134537

Iyer NV, Kotch LE, Agani F, Leung SW, Laughner E, Wenger RH, Gassmann M, Gearhart JD, Lawler AM, Yu AY, Semenza GL (1998) Cellular and developmental control of O2 homeostasis by hypoxia-inducible factor 1 alpha. Genes Dev 12: 149-162. https:// doi.org/10.1101/gad.12.2.149 
Jäger S, Handschin C, St-Pierre J, Spiegelman BM (2007) AMP-activated protein kinase (AMPK) action in skeletal muscle via direct phosphorylation of PGC-1alpha. Proc Natl Acad Sci USA 104: $12017-$ 1222. https://doi.org/10.1073/pnas.0705070104

Jha AK, Huang SC-C, Sergushichev A, Lampropoulou V, Ivanova Y, Loginicheva E, Chmielewski K, Stewart KM, Ashall J, Everts B, Pearce EJ, Driggers EM, Artyomov MN (2015) Network integration of parallel metabolic and transcriptional data reveals metabolic modules that regulate macrophage polarization. Immunity 42: 419-430. https://doi.org/10.1016/j.immuni.2015.02.005

Jiang H, Guo R, Powell-Coffman JA (2001) The Caenorbabditis elegans hif-1 gene encodes a bHLH-PAS protein that is required for adaptation to hypoxia. Proc Natl Acad Sci USA 98: 7916-7921. https:// doi.org/10.1073/pnas.141234698

Jones RG, Plas DR, Kubek S, Buzzai M, Mu J, Xu Y, Birnbaum MJ, Thompson CB (2005) AMP-activated protein kinase induces a p53dependent metabolic checkpoint. Mol Cell 18: 283-293. https://doi. org/10.1016/i.molcel.2005.03.027

Kabrun N, Buhring HJ, Choi K, Ullrich A, Risau W, Keller G (1997) Flk-1 expression defines a population of early embryonic hematopoietic precursors. Development 124: 2039-2048

Kajiwara C, Kusaka Y, Kimura S, Yamaguchi T, Nanjo Y, Ishii Y, Udono H, Standiford TJ, Tateda K (2018) Metformin mediates protection against Legionella pneumonia through activation of AMPK and mitochondrial reactive oxygen species. I Immunol 200: 623-631. https://doi.org/10.4049/jimmunol.1700474

Kallio PJ, Okamoto K, O’Brien S, Carrero P, Makino Y, Tanaka H, Poellinger L (1998) Signal transduction in hypoxic cells: inducible nuclear translocation and recruitment of the CBP/p300 coactivator by the hypoxia-inducible factor- $1 \alpha$. EMBO J 17: 6573-6586. https://doi.org/10.1093/emboj/17.22.6573

Kardon T, Stroobant V, Veiga-da-Cunha M, Schaftingen EV (2008) Characterization of mammalian sedoheptulokinase and mechanism of formation of erythritol in sedoheptulokinase deficiency. FEBS Lett 582: 3330-3334. https://doi.org/10.1016/i.febslet.2008.08.024

Kativar S, Liu E, Knutzen CA, Lang ES, Lombardo CR, Sankar S, Toth JI, Petroski MD, Ronai Z, Chiang GG (2009) REDD1, an inhibitor of mTOR signalling, is regulated by the CUL4A-DDB1 ubiquitin ligase. EMBO Rep 10: 866-872. https://doi.org/10.1038/ embor.2009.93

Kauppinen A, Suuronen T, Ojala J, Kaarniranta K, Salminen A (2013) Antagonistic crosstalk between NF- $x$ B and SIRT1 in the regulation of inflammation and metabolic disorders. Cell Signal 25: 1939-1948. https://doi.org/10.1016/j.cellsig.2013.06.007

Keller MA, Turchyn AV, Ralser M (2014) Non-enzymatic glycolysis and pentose phosphate pathway-like reactions in a plausible Archean ocean. Mol Syst Biol 10: 725. https://doi.org/10.1002/msb.20145228

Kelly TJ, Lerin C, Haas W, Gygi SP, Puigserver P (2009) GCN5-mediated transcriptional control of the metabolic coactivator PGC-1 $\beta$ through lysine acetylation. J Biol Chem 284: 19945-19952. https:// doi.org/10.1074/jbc.M109.015164

Kemphues KJ, Priess JR, Morton DG, Cheng NS (1988) Identification of genes required for cytoplasmic localization in early $C$ e egans embryos. Cell 52: 311-320. https://doi.org/10.1016/s00928674(88)80024-2

Kilani MM, Mohammed KA, Nasreen N, Tepper RS, Antony VB (2004) RSV causes HIF- 1alpha stabilization via NO release in primary bronchial epithelial cells. Inflammation 28: 245-251. https://doi. org/10.1007/s10753-004-6047-y

Kim JW, Tchernyshyov I, Semenza GL, Dang CV (2006) HIF-1-mediated expression of pyruvate dehydrogenase kinase: a metabolic switch required for cellular adaptation to hypoxia. Cell Metab 3 177-185. https://doi.org/10.1016/j.cmet.2006.02.002

Kimura T, Nada S, Takegahara N, Okuno T, Nojima S, Kang S Ito D, Morimoto K, Hosokawa T, Hayama Y, Mitsui Y, Sakurai N, Sarashina-Kida H, Nishide M, Maeda Y, Takamatsu H, Okuzaki D, Yamada M, Okada M, Kumanogoh A (2016) Polarization of M2 macrophages requires Lamtor1 that integrates cytokine and amino-acid signals. Nat Commun 7: 1-15. https://doi.org/10.1038/ ncomms 13130

Kiosses WB, Daniels RH, Otey C, Bokoch GM, Schwartz MA (1999) A role for p21-activated kinase in endothelial cell migration. J Cell Biol 147: 831-844. https://doi.org/10.1083/jcb.147.4.831

Kita K, Hirawake H, Mivadera H, Amino H, Takeo S (2002) Role of complex II in anaerobic respiration of the parasite mitochondria from Ascaris suum and Plasmodium falciparum. Biochim Biophys Acta 1553: 123-139. https://doi.org/10.1016/s0005-2728(01)00237-7

Kita K, Takamiya S (2002) Electron-transfer complexes in Ascaris mitochondria. Adv Parasitol 51: 95-131. https://doi.org/10.1016/ s0065-308x(02) 51004-6

Kjellin J, Pränting M, Bach F, Vaid R, Edelbroek B, Li Z, Hoeppner MP, Grabherr M, Isberg RR, Hagedorn M, Söderbom F (2019) Investigation of the host transcriptional response to intracellular bacterial infection using Dictyostelium discoideum as a host model. BMC Genomics 20: 961. https://doi.org/10.1186/s12864-019-6269-x
Knight M, Stanley S (2019) HIF-1 $\alpha$ as a central mediator of cellular resistance to intracellular pathogens. Curr Opin Immunol 60: 111-116. https://doi.org/10.1016/j.coi.2019.05.005

Krawczyk CM, Holowka T, Sun J, Blagih J, Amiel E, DeBerardinis RJ, Cross JR, Jung E, Thompson CB, Jones RG, Pearce EJ (2010) Toll-like receptor-induced changes in glycolytic metabolism regulate dendritic cell activation. Blood 115: 4742-4749. https://doi.org/ org/10.1182/blood-2009-10-249540

Lachmandas E, Boutens L, Ratter JM, Hijmans A, Hooiveld GJ, Joosten LA, Rodenburg RJ, Fransen JA, Houtkooper RH, van Crevel R, Netea MG, Stienstra R (2016) Microbial stimulation of different Toll-like receptor signalling pathways induces diverse metabolic programmes in human monocytes. Nat Microbiol 2: 16246. https://doi. org/10.1038/nmicrobiol.2016.246

Laplante M, Sabatini DM (2012) mTOR signaling in growth control and disease. Cell 149: 274-293. https://doi.org/10.1016/j. cell.2012.03.017

Laughner E, Taghavi P, Chiles K, Mahon PC, Semenza GL (2001) HER2 (neu) signaling increases the rate of hypoxia-inducible factor 1 alpha (HIF-1alpha) synthesis: novel mechanism for HIF-1-mediated vascular endothelial growth factor expression. Mol Cell Biol 21: 3995-4004. https://doi.org/10.1128/MCB.21.12.3995-4004.2001

Leach RM, Treacher DF (1998) Oxygen transport-2. Tissue hypoxia. BMJ 317: 1370-1373. https://doi.org/10.1136/bmj.317.7169.1370

Lee JH, Koh H, Kim M, Kim Y, Lee SY, Karess RE, Lee SH, Shong M, Kim JM, Kim J, Chung J (2007) Energy-dependent regulation of cell structure by AMP-activated protein kinase. Nature 447: 10171020. https://doi.org/10.1038/nature05828

Li JH, Shao JZ, Xiang LX, Wen Y (2007) Cloning, characterization and expression analysis of pufferfish interleukin-4 cDNA: the first evidence of Th2-type cytokine in fish. Mol Immunol 44: 2078-2086. https://doi.org/10.1016/j.molimm.2006.09.010

Li P, Vassiliadis D, Ong SY, Bennett-Wood V, Sugimoto C, Yamagishi J, Hartland EL, Pasricha S (2020) Legionella pneumophila infection rewires the Acanthamoeba castellanii transcriptome, highlighting a class of Sirtuin Genes. Front Cell Infect Microbiol 10: 428. https://doi. org $/ 10.3389 /$ fcimb. 2020.00428

Liaud MF, Lichtlé C, Apt K, Martin W, Cerff R (2000) Compartmentspecific isoforms of TPI and GAPDH are imported into diatom mitochondria as a fusion protein: evidence in favor of a mitochondrial origin of the eukaryotic glycolytic pathway. Mol Biol Evol 17: 213-223. https://doi.org/10.1093/oxfordjournals.molbev.a026301

Liu F, Thatcher JD, Barral JM, Epstein HF (1995) Bifunctional glyoxylate cycle protein of Caenorbabditis elegans: a developmentally regulated protein of intestine and muscle. Dev Biol 169: 399-414. https:// doi.org/10.1006/dbio.1995.1156

Liu L. Simon MC (2004) Regulation of transcription and translation by hypoxia. Cancer Biol Ther 3: 492-497. https://doi.org/10.4161/ cbt.3.6.1010

Liu YV, Semenza GL (2007) RACK1 vs. HSP90: competition for HIF1 alpha degradation vs. stabilization. Cell Cycle 6: 656-659. https:// doi.org/10.4161/cc.6.6.3981

Lizcano JM, Göransson O, Toth R, Deak M, Morrice NA, Boudeau J, Hawley SA, Udd L, Mäkelä TP, Hardie DG, Alessi DR (2004) LKB1 is a master kinase that activates 13 kinases of the AMPK subfamily, including MARK/PAR-1. EMBO J 23: 833-843. https:// doi.org/10.1038/sj.emboj.7600110

Loboda A, Józkowicz A, Dulak J (2012) HIF-1 versus HIF-2 is one more important than the other? Vascul Pharmacol 56: 245-251. https://doi.org/10.1016/j.vph.2012.02.006

Mahon PC, Hirota K, Semenza GL (2001) FIH-1: a novel protein that interacts with HIF-1alpha and VHL to mediate repression of HIF-1 transcriptional activity. Genes Dev 15: 2675-2686. https://doi. org/10.1101/gad.924501

Marsin AS, Bouzin C, Bertrand L, Hue L (2002) The stimulation of glycolysis by hypoxia in activated monocytes is mediated by AMP-activated protein kinase and inducible 6-phosphofructo-2-kinase. J Biol Chem 277: 30778-30783. https://doi.org/10.1074/jbc. M205213200

Martin M, Rehani K, Jope RS, Michalek SM (2005) Toll-like receptormediated cytokine production is differentially regulated by glycogen synthase kinase 3. Nat Immunol 6: 777-784. https://doi.org/ $10.1038 /$ ni1221

Mathews CK, van Holde KE, Appling DR, Anthony-Cahill SJ (2013) Biochemistry. Pearson ed, 4th edn

Mesquita I, Moreira D, Sampaio-Marques B, Laforge M, Cordeiroda-Silva A, Ludovico P, Estaquier J, Silvestre R (2016) AMPK in Pathogens. Exp Suppl 107: 287-323. https://doi.org/10.1007/978-3319-43589-3_12

Miclet E, Stoven V, Michels PA, Opperdoes FR, Lallemand JY, Duffieux F (2001) NMR spectroscopic analysis of the first two steps of the pentose-phosphate pathway elucidates the role of 6-phosphogluconolactonase. I Biol Chem 276: 34840-34846. https://doi. org/10.1074/ibc.M105174200

Miller DJ, Hemmrich G, Ball EE, Hayward DC, Khalturin K, Funayama N, Agata K, Bosch TC (2007) The innate immune repertoire in 
cnidarian-ancestral complexity and stochastic gene loss. Genome Biol 8: R59. https://doi.org/10.1186/gb-2007-8-4-r59

Mills EL, Kelly B, Logan A, Costa ASH, Varma M, Bryant CE, Tourlomousis P, Däbritz JHM, Gottlieb E, Latorre I, Corr SC, McManus G, Ryan D, Jacobs HT, Szibor M, Xavier RJ, Braun T, Frezza C, Murphy MP, O’Neill LA (2016) Succinate dehydrogenase supports metabolic repurposing of mitochondria to drive inflammatory macrophages. Cell 167: 457-470. e13. https://doi.org/10.1016/j. cell.2016.08.064

Miyadera H, Hiraishi A, Miyoshi H, Sakamoto K, Mineki R, Murayama K, Nagashima KV, Matsuura K, Kojima S, Kita K (2003) Complex II from phototrophic purple bacterium Rhodoferax fermentans displays rhodoquinol-fumarate reductase activity. Eur J Biochem 270: 18631874. https://doi.org/10.1046/j.1432-1033.2003.03553.x

Moreira D, Rodrigues V, Abengozar M, Rivas L, Rial E, Laforge M, Li X, Foretz M, Viollet B, Estaquier J, Cordeiro da Silva A, Silvestre $\mathrm{R}$ (2015) Leishmania infantum modulates host macrophage mitochondrial metabolism by hijacking the SIRT1-AMPK axis. PLoS Pathog. 11: e1004684. https://doi.org/10.1371/journal.ppat.1004684

Morton DG, Roos JM, Kemphues KJ (1992) par-4, a gene required for cytoplasmic localization and determination of specific cell types in Caenorhabditis elegans embryogenesis. Genetics 130: 771-790

Müller M, Mentel M, van Hellemond JJ, Henze K, Woehle C, Gould SB, Yu RY, van der Giezen M, Tielens AG, Martin WF (2012) Biochemistry and evolution of anaerobic energy metabolism in eukaryotes. Microbiol Mol Biol Rev 76: 444-495. https://doi.org/10.1128/ MMBR.05024-11

Murray PJ, Wynn TA (2011) Protective and pathogenic functions of macrophage subsets. Nat Rev Immunol 11: 723-737. https://doi. org/10.1038/nri3073

Mylonas KJ, Nair MG, Prieto-Lafuente L, Paape D, Allen JE (2009) Alternatively activated macrophages elicited by helminth infection can be reprogrammed to enable microbial killing. J Immunol 182: 3084-3094. https://doi.org/10.4049/jimmunol.0803463

Nakano A, Kato H, Watanabe T, Min KD, Yamazaki S, Asano Y, Seguchi O, Higo S, Shintani Y, Asanuma H, Asakura M, Minamino T, Kaibuchi K, Mochizuki N, Kitakaze M, Takashima S (2010) AMPK controls the speed of microtubule polymerization and directional cell migration through CLIP-170 phosphorylation. Nat Cell Biol 12: 583-590. https://doi.org/10.1038/ncb2060

Nakano A, Takashima S (2012) LKB1 and AMP-activated protein kinase: regulators of cell polarity. Genes Cells 17: 737-747. https://doi. org/10.1111/j.1365-2443.2012.01629.x

Narbonne P, Roy R (2006) Inhibition of germline proliferation during C. elegans dauer development requires PTEN, LKB1 and AMPK signalling. Development 133: 611-619. https://doi.org/10.1242/ dev.02232

Nathan C (1992) Nitric oxide as a secretory product of mammalian cells. FASEB I 6: 3051-3064

Neumann D (2018) Is TAK1 a Direct Upstream Kinase of AMPK? Int J Mol Sci 19: 2412. https://doi.org/10.3390/ijms19082412

Newsholme P, Curi R, Gordon S, Newsholme EA (1986) Metabolism of glucose, glutamine, long-chain fatty acids and ketone bodies by murine macrophages. Biochem J 239: 121-125. https://doi. org/10.1042/bj2390121

Nieves W, Hung LY, Oniskey TK, Boon L, Foretz M, Viollet B, Herbert DR (2016) Myeloid-restricted AMPK $\alpha 1$ promotes host immunity and protects against IL-12/23p40-dependent lung injury during hookworm infection. J Immunol 196: 4632-4640. https://doi. org/10.4049/jimmunol.1502218

Nizet V, Johnson RS (2009) Interdependence of hypoxic and innate immune responses. Nat Rev Immunol 9: 609-617. https://doi. org $/ 10.1038 /$ nri2607

Noritake J, Watanabe T, Sato K, Wang S, Kaibuchi K (2005) IQGAP1: a key regulator of adhesion and migration. J Cell Sci 118: 2085-2092. https://doi.org/10.1242/jcs.02379

Oakhill JS, Steel R, Chen ZP, Scott JW, Ling N, Tam S, Kemp BE (2011) AMPK is a direct adenylate charge-regulated protein kinase. Science 332: 1433-1435. https://doi.org/10.1126/science.1200094

Okazaki K, Maltepe E (2006) Oxygen, epigenetics and stem cell fate. Regen Med 1: 71-83. https://doi.org/10.2217/17460751.1.1.71

O’Neill LA, Hardie DG (2013) Metabolism of inflammation limited by AMPK and pseudo-starvation. Nature 493: 346-355. https://doi. org/10.1038/nature11862

O’Neill LAJ, Pearce EJ (2016) Immunometabolism governs dendritic cell and macrophage function. J Exp Med 213: 15-23. https://doi. org/10.1084/jem.20151570

Palsson-McDermott EM, Curtis AM, Goel G, Lauterbach MAR, Sheedy FJ, Gleeson LE, van den Bosch MWM, Quinn SR, Domingo-Fernandez R, Johnston DGW, Jiang JK, Israelsen WJ, Keane J, Thomas C, Clish C, Vander Heiden M, Xavier RJ, O’Neill LAJ (2015) Pyruvate kinase M2 regulates Hif- $1 \alpha$; activity and IL$1 \beta$; induction and is a critical determinant of the Warburg effect in LPS-activated macrophages. Cell Metab 21: 65-80. https://doi. org/10.1016/j.cmet.2014.12.005
Pan DA, Hardie DG (2002) A homologue of AMP-activated protein kinase in Drosophila melanogaster is sensitive to AMP and is activated by ATP depletion. Biochem J 367: 179-186. https://doi.org/10.1042/ BJ20020703

Papandreou I, Cairns RA, Fontana L, Lim AL, Denko NC (2006) HIF-1 mediates adaptation to hypoxia by actively downregulating mitochondrial oxygen consumption. Cell Metab 3: 187-197. https:// doi.org/10.1016/j.cmet.2006.01.012

Peyssonnaux C, Boutin AT, Zinkernagel AS, Datta V, Nizet V, Johnson RS (2008) Critical role of HIF-1alpha in keratinocyte defense against bacterial infection. J Invest Dermatol 128: 1964-1968. https:// doi.org/10.1038/jid.2008.27

Peyssonnaux C, Cejudo-Martin P, Doedens A, Zinkernagel AS, Johnson RS, Nizet V (2007) Cutting edge: Essential role of hypoxia inducible factor-1alpha in development of lipopolysaccharide-induced sepsis. J Immunol 178: 7516-7519. https://doi.org/10.4049/jimmunol.178.12.7516

Peyssonnaux C, Datta V, Cramer T, Doedens A, Theodorakis EA, Gallo RL, Hurtado-Ziola N, Nizet V, Johnson RS (2005) HIF-1alpha expression regulates the bactericidal capacity of phagocytes. $J$ Clin Invest 115: 1806-1815. https://doi.org/10.1172/JCI23865

Piret JP, Mottet D, Raes M, Michiels C (2002) Is HIF-1alpha a proor an anti-apoptotic protein? Biochem Pharmacol 64: 889-892. doi: 10.1016/s0006-2952(02)01155-3

Price CT, Al-Quadan T, Santic M, Rosenshine I, Abu Kwaik Y (2011) Host proteasomal degradation generates amino acids essential for intracellular bacterial growth. Science 334: 1553-1557. https://doi. org/10.1126/science.1212868

Price CT, Abu Kwaik Y (2014) The transcriptome of Legionella pneumophila-infected human monocyte-derived macrophages. PLoS One 9: e114914. https://doi.org/10.1371/journal.pone.0114914

Qualls JE, Subramanian C, Rafi W, Smith AM, Balouzian L, DeFreitas AA, Shirey KA, Reutterer B, Kernbauer E, Stockinger S, Decker T, Miyairi I, Vogel SN, Salgame P, Rock CO, Murray PJ (2012) Sustained generation of nitric oxide and control of mycobacterial infection requires argininosuccinate synthase 1. Cell Host and Microbe 12: 313-323. https://doi.org/10.1016/j.chom.2012.07.012

Rabhi I, Rabhi S, Ben-Othman R, Rasche A, Daskalaki A, Trentin B, Piquemal D, Regnault B, Descoteaux A, Guizani-Tabbane L, Sysco Consortium (2012) Transcriptomic signature of Leishmania infected mice macrophages: a metabolic point of view. PLoS Negl Trop Dis. 6: e1763. https://doi.org/10.1371/journal.pntd.0001763

Rehorn KP, Thelen H, Michelson AM, Reuter R (1996) A molecular aspect of hematopoiesis and endoderm development common to vertebrates and Drosophila. Development 122: 4023-4031

Ridley AJ, Schwartz MA, Burridge K, Firtel RA, Ginsberg MH, Borisy G, Parsons JT, Horwitz AR (2003) Cell migration: integrating signals from front to back. Science 302: 1704-1709. https://doi. org/10.1126/science.1092053

Rodriguez OC, Schaefer AW, Mandato CA, Forscher P, Bement WM, Waterman-Storer CM (2003) Conserved microtubule-actin interactions in cell movement and morphogenesis. Nat Cell Biol 5: 599609. https://doi.org/10.1038/ncb0703-599

Rodríguez-Prados JC, Través PG, Cuenca J, Rico D, Aragonés J, Martín-Sanz P, Cascante M, Boscá L (2010) Substrate fate in activated macrophages: a comparison between innate, classic, and alternative activation. J Immunol 185: 605-614. https://doi.org/10.4049/jimmunol.0901698

Romano AH, Conway T (1996) Evolution of carbohydrate metabolic pathways. Res Microbiol 147: 448-455. https://doi.org/10.1016/09232508(96)83998-2

Ronimus RS, Morgan HW (2003) Distribution and phylogenies of enzymes of the Embden- Meyerhof-Parnas pathway from archaea and hyperthermophilic bacteria support a gluconeogenic origin of metabolism. Archaea 1: 199-221. https://doi.org/10.1155/2003/162593

Roos MH, Tielens AG (1994) Differential expression of two succinate dehydrogenase subunit-B genes and a transition in energy metabolism during the development of the parasitic nematode Haemonchus contortus. Mol Biochem Parasitol 66: 273-281. https://doi. org/10.1016/0166-6851(94)90154-6

Roustan V, Jain A, Teige M, Ebersberger I, Weckwerth W (2016) An evolutionary perspective of AMPK-TOR signaling in the three domains of life. J Exp Bot 67: 3897-3907. https://doi.org/10.1093/ jxb/erw211

Rupp J, Gieffers J, Klinger M, van Zandbergen G, Wrase R, Maass M, Solbach W, Deiwick J, Hellwig-Burgel T (2007) Chlamydia pneumoniae directly interferes with HIF-1alpha stabilization in human host cells. Cell Microbiol 9: 2181-2191. https://doi.org/10.1111/j.14625822.2007.00948.x

Ryan HE, Lo J, Johnson RS (1998) HIF-1 alpha is required for solid tumor formation and embryonic vascularization. EMBO J 17: 30053015. https://doi.org/10.1093/emboj/17.11.3005

Rytkönen KT, Storz JF (2011) Evolutionary origins of oxygen sensing in animals. EMBO Rep 12: 3-4. https://doi.org/10.1038/embor. 2010.192 
Rytkönen KT, Vuori KA, Primmer CR, Nikinmaa M (2007) Comparison of hypoxia-inducible factor- 1 alpha in hypoxia-sensitive and hypoxia-tolerant fish species. Comp Biochem Physiol Part D Genomics Proteomics 2: 177-186. https://doi.org/10.1016/j.cbd.2007.03.001

Sag D, Carling D, Stout RD, Suttles J (2008). Adenosine 5'-monophosphate-activated protein kinase promotes macrophage polarization to an anti-inflammatory functional phenotype. I Immunol 181: 86338641. https://doi.org/10.4049/ jimmunol.181.12.8633

Sakai C, Tomitsuka E, Esumi H, Harada S, Kita K (2012) Mitochondrial fumarate reductase as a target of chemotherapy: from parasites to cancer cells. Biochim Biophys Acta 1820: 643-651. https://doi. org/10.1016/j.bbagen.2011.12.013

Salinas G, Langelaan DN, Shepherd JN. (2020) Rhodoquinone in bacteria and animals: Two distinct pathways for biosynthesis of this key electron transporter used in anaerobic bioenergetics. Biochim Biophys Acta 1861: 148278. https://doi.org/10.1016/j.bbabio.2020.148278

Sancak Y, Peterson TR, Shaul YD, Lindquist RA, Thoreen CC, BarPeled L, Sabatini DM (2008) The Rag GTPases bind raptor and mediate amino acid signaling to mTORC1. Science 320: 1496-1501. https://doi.org/10.1126/science.1157535

Schunder E, Gillmaier N, Kutzner E, Eisenreich W, Herrmann V, Lautner M, Heuner K (2014) Amino acid uptake and metabolism of Legionella pneumophila hosted by Acanthamoeba castellanii. J Biol Chem 289: 21040-21054. https://doi.org/10.1074/jbc.M114.570085

Seagroves TN, Ryan HE, Lu H, Wouters BG, Knapp M, Thibault P, Laderoute K, Johnson RS (2001) Transcription factor HIF-1 is a necessary mediator of the Pasteur effect in mammalian cells. Mol Cell Biol 21: 3436-3444. https://doi.org/10.1128/MCB.21.10.34363444.2001

Semba H, Takeda N, Isagawa T, Sugiura Y, Honda K, Wake M, Miyazawa $H$, Yamaguchi $Y$, Miura M, Jenkins DM, Choi H, Kim JW, Asagiri M, Cowburn AS, Abe H, Soma K, Koyama K, Katoh M, Sayama K, Goda N, Johnson RS, Manabe I, Nagai R, Komuro I (2016) HIF-1 $\alpha$-PDK1 axis-induced active glycolysis plays an essential role in macrophage migratory capacity. Nat Commun 7: 11635. https://doi.org/10.1038/ncomms11635

Semenza GL (2002) HIF-1 and tumor progression: pathophysiology and therapeutics. Trends Mol Med. 8: S62-S67. https://doi org/10.1016/s1471-4914(02)02317-1

Semenza GL (2007) Hypoxia-inducible factor 1 (HIF-1) pathway. Sci STKE 2007(407):cm8. https://doi.org/10.1126/stke.4072007cm8

Semenza GL (2012) Hypoxia-inducible factors in physiology and medicine. Cell 148: 399-408. doi: 10.1016/j.cell.2012.01.021

Shams I, Avivi A, Nevo E (2004) Hypoxic stress tolerance of the blind subterranean mole rat: expression of erythropoietin and hypoxiainducible factor 1 alpha. Proc Natl Acad Sci USA 101: 9698-9703. https://doi.org/10.1073/pnas.0403540101

Shen C, Nettleton D, Jiang M, Kim SK, Powell-Coffman JA (2005) Roles of the HIF-1 hypoxia-inducible factor during hypoxia response in Caenorhabditis elegans. I Biol Chem 280: 20580-20588. https://doi.org/10.1074/jbc.M501894200

Siegl C, Prusty BK, Karunakaran K, Wischhusen J, Rudel T (2014) Tumor suppressor p53 alters host cell metabolism to limit Chlamydia trachomatis infection. Cell Rep 9: 918-929. https://doi.org/10.1016/j. celrep.2014.10.004

Singh V, Jamwal S, Jain R, Verma P, Gokhale R, Rao KV (2012) Mycobacterium tuberculosis-driven targeted recalibration of macrophage lipid homeostasis promotes the foamy phenotype. Cell Host Microbe 12: 669-681. https://doi.org/10.1016/j.chom.2012.09.012

Sinnett SE, Brenman JE (2016) The Role of AMPK in Drosopbila melanogaster. Exp Suppl. 107: 389-401. https://doi.org/10.1007/978-3319-43589-316

Solaini G, Baracca A, Lenaz G, Sgarbi G (2010) Hypoxia and mitochondrial oxidative metabolism. Biochim Biophys Acta 1797: 11711177. https://doi.org/10.1016/j.bbabio.2010.02.011

Spear W, Chan D, Coppens I, Johnson RS, Giaccia A, Blader IJ (2006) The host cell transcription factor hypoxia-inducible factor 1 is required for Toxoplasma gondii growth and survival at physiological oxygen levels. Cell Microbiol 8: 339-352. https://doi.org/10.1111/ j.1462-5822.2005.00628.x

Staples KJ, Sotoodehnejadnematalahi F, Pearson H, Frankenberger M, Francescut L, Ziegler- Heitbrock L, Burke B (2011) Monocytederived macrophages matured under prolonged hypoxia transcriptionally up-regulate HIF-1 $\alpha$ mRNA. Immunobiology 216: 832-839. https://doi.org/10.1016/j.imbio.2010.12.005

Sutter CH, Laughner E, Semenza GL (2000). Hypoxia-inducible factor 1 alpha protein expression is controlled by oxygen-regulated ubiquitination that is distupted by deletions and missense mutations. Proc Natl Acad Sci USA 97: 4748-4753. https://doi.org/10.1073/ pnas.080072497

Suzuki T, Bridges D, Nakada D, Skiniotis G, Morrison SJ, Lin JD, Saltiel AR, Inoki K (2013) Inhibition of AMPK catabolic action by GSK3. Mol Cell 50: 407-419. https://doi.org/10.1016/j.molcel.2013.03.022

Tan Z, Xie N, Cui H, Moellering DR, Abraham E, Thannickal VJ, Liu G (2015) Pyruvate dehydrogenase kinase 1 participates in mac- rophage polarization via regulating glucose metabolism. I Immuno 194: 6082-6089. https://doi.org/10.4049/jimmunol.1402469

Tannahill GM, Curtis AM, Adamik J, Palsson-McDermott EM, McGettrick AF, Goel G, Frezza C, Bernard NJ, Kelly B, Foley NH, Zheng L, Gardet A, Tong Z, Jany SS, Corr SC, Haneklaus M, Caffrey BE, Pierce K, Walmsley S, Beasley FC, Cummins E, Nizet V, Whyte M, Taylor CT, Lin H, Masters SL, Gottlieb E, Kelly VP, Clish C, Auron PE, Xavier RJ, O’Neill LA (2013) Succinate is an inflammatory signal that induces IL-1 $\beta$ through HIF-1 $\alpha$. Nature 496: 238-242. https://doi.org/10.1038/nature11986

Tesh MJ, Morse SA, Miller RD (1983) Intermediary metabolism in Legionella pneumophila: utilization of amino acids and other compounds as energy sources. J Bacteriol 154: 1104-1109. https://doi. org/10.1128/JB.154.3.1104-1109.1983

Thrash JC, Boyd A, Huggett MJ, Grote J, Carini P, Yoder RJ, Robbertse B, Spatafora JW, Rappé MS, Giovannoni SJ (2011) Phylogenomic evidence for a common ancestor of mitochondria and the SAR11 clade. Sci Rep 1: 13. https://doi.org/10.1038/srep00013

Tielens AG, Van Hellemond JJ (1998) The electron transport chain in anaerobically functioning eukaryotes. Biochim Biophys Acta 1365: 7178. https://doi.org/org/10.1016/S0005- 2728(98)00045-0

Tomitsuka E, Kita K, Esumi H (2009) Regulation of succinate-ubiquinone reductase and fumarate reductase activities in human complex II by phosphorylation of its flavoprotein subunit. Proc Jpn Acad Ser B Phys Biol Sci 85: 258-265. https://doi.org/10.2183/pjab.85.258

Tsang AP, Visvader JE, Turner CA, Fujiwara Y, Yu C, Weiss MJ, Crossley M, Orkin SH (1997) FOG, a multitype zinc finger protein, acts as a cofactor for transcription factor GATA-1 in erythroid and megakaryocytic differentiation. Cell 90: 109-119. https://doi. org/10.1016/S0092-8674(00)80318-9

Ullah MS, Davies AJ, Halestrap AP (2006) The plasma membrane lactate transporter MCT4, but not MCT1, is up-regulated by hypoxia through a HIF-1alpha-dependent mechanism. I Biol Chem 281: 9030-9037. https://doi.org/10.1074/jbc.M511397200

Van Hellemond JJ, Klockiewicz M, Gaasenbeek CP, Roos MH, Tielens AG (1995) Rhodoquinone and complex II of the electron transport chain in anaerobically functioning eukaryotes. $J$ Biol Chem 270: 31065-31070. https://doi.org/10.1074/jbc.270.52.31065

Vander Heiden MG, Cantley LC, Thompson CB (2009) Understanding the Warburg effect: the metabolic requirements of cell proliferation. Science 324: 1029-1033. https://doi.org/10.1126/science.1160809

Vats D, Mukundan L, Odegaard JI, Zhang L, Smith KL, Morel CR, Wagner RA, Greaves DR, Murray PJ, Chawla A (2006) Oxidative metabolism and PGC-1beta attenuate macrophage-mediated inflammation. Cell Metab 4: 13-24. https://doi.org/10.1016/j. cmet.2006.05.011

Vazquez-Martin A, Oliveras-Ferraros C, Menendez JA (2009 a) The active form of the metabolic sensor: AMP-activated protein kinase (AMPK) directly binds the mitotic apparatus and travels from centrosomes to the spindle midzone during mitosis and cytokinesis. Cell Cycle 8: 2385-2398. https://doi.org/org/10.4161/cc.8.15.9082

Vazquez-Martin A, López-Bonet E, Oliveras-Ferraros C, Pérez-Martínez MC, Bernadó L, Menendez JA (2009b) Mitotic kinase dynamics of the active form of AMPK (phospho-AMPKalphaThr172) in human cancer cells. Cell Cycle 8: 788-791. https://doi.org/10.4161/ cc.8.5.7787

Visvader JE, Crossley M, Hill J, Orkin SH, Adams JM (1995) The Cterminal zinc finger of GATA-1 or GATA-2 is sufficient to induce megakaryocytic differentiation of an early myeloid cell line. Mol Cell Biol 15: 634-641. https://doi.org/10.1128/mcb.15.2.634

Waltzer L, Bataillé L, Peyrefitte S, Haenlin M (2002) Two isoforms of Serpent containing either one or two GATA zinc fingers have different roles in Drosopbila haematopoiesis. EMBO J 21: 5477-5486. https://doi.org/10.1093/emboj/cdf545

Wałajtys-Rode E, Dzik JM (2017) Monocyte/Macrophage: NK cell cooperation-old tools for new functions. Results Probl Cell Differ 62: 73-145. doi: 10.1007/978-3-319-54090- 0 5

Wamelink MM, Struys EA, Jakobs C (2008) The biochemistry, metabolism and inherited defects of the pentose phosphate pathway: a review. J Inherit Metab Dis 31: 703-717. https://doi.org/10.1007/ s10545-008-1015-6

Wang T, Secombes CJ (2015) The evolution of IL-4 and IL-13 and their receptor subunits. Cytokine 75: 8-13. https://doi. org/10.1016/j.cyto.2015.04.012.

Wang GL, Semenza GL (1993) Desferrioxamine induces erythropoietin gene expression and hypoxia-inducible factor 1 DNA binding activity: Implications for models of hypoxia signal transduction. Blood 82: 3610-3615. https://doi.org/org/10.1182/blood.V82.12.3610.3610

Wang T, Liu H, Lian G, Zhang SY, Wang X, Jiang C (2017) HIF1ainduced glycolysis metabolism is essential to the activation of inflammatory macrophages. Mediators Inflamm 2017: 9029-327. https:// doi.org/10.1155/2017/9029327

Warburg OH (1947) Ideen zur Fermentchemie der Tumoren. Akademie-Verlag, Berlin, Germany 
Ward PS, Thompson CB (2012) Metabolic reprogramming: a cancer hallmark even Warburg did not anticipate. Cancer Cell 21: 297-308. https://doi.org/10.1016/j.ccr.2012.02.014

Watanabe T, Wang S, Noritake J, Sato K, Fukata M, Takefuji M, Nakagawa M, Izumi N, Akiyama T, Kaibuchi K (2004) Interaction with IQGAP1 links APC to Rac1, Cdc42, and actin filaments during cell polarization and migration. Dev Cell 7: 871-83. https://doi. org/10.1016/j.devcel.2004.10.017

Weinberg JM, Venkatachalam MA, Roeser NF, Nissim I (2000) Mitochondrial dysfunction during hypoxia/reoxygenation and its correction by anaerobic metabolism of citric acid cycle intermediates. Proc Natl Acad Sci USA 97: 2826-2831. https://doi.org/10.1073/ pnas.97.6.2826

West AP, Brodsky IE, Rahner C, Woo DK, Erdjument-Bromage H, Tempst P, Walsh MC, Choi Y, Shadel GS, Ghosh S (2011) TLR signalling augments macrophage bactericidal activity through mitochondrial ROS. Nature 472: 476-480. https://doi.org/10.1038/nature09973

Wightman PD, Dallob A (1990) Regulation of phosphatidylinositol breakdown and leukotriene synthesis by endogenous prostaglandins in resident mouse peritoneal macrophages. J Biol Chem 265: 91769180

Wilson WA, Hawley SA, Hardie DG (1996) Glucose repression/ derepression in budding yeast: SNF1 protein kinase is activated by phosphorylation under derepressing conditions, and this correlates with a high AMP:ATP ratio. Curr Biol 6: 1426-1434. https://doi. org/10.1016/s0960-9822(96)00747-6

Wittmann T, Bokoch GM, Waterman-Storer CM (2003) Regulation of leading edge microtubule and actin dynamics downstream of Rac1. J Cell Biol 161: 845-851. https://doi.org/10.1083/jcb.200303082

Wood AP, Aurikko JP, Kelly DP (2004) A challenge for 21st century molecular biology and biochemistry: what are the causes of obligate autotrophy and methanotrophy? FEMS Microbiol Rev 28: 335-352. doi: 10.1016/j.femsre.2003.12.001

Woods A, Munday MR, Scott J, Yang X, Carlson M, Carling D (1994) Yeast SNF1 is functionally related to mammalian AMP-activated protein kinase and regulates acetyl-CoA carboxylase in vivo. J Biol Chem 269: 19509-19515

Wu Z, Puigserver P, Andersson U, Zhang C, Adelmant G, Mootha V, Troy A, Cinti S, Lowell B, Scarpulla RC, Spiegelman BM (1999)
Mechanisms controlling mitochondrial biogenesis and respiration through the thermogenic coactivator PGC-1. Cell 98: 115-124. https://doi.org/10.1016/S0092-8674(00)80611-X

Wullschleger S, Loewith R, Hall MN (2006) TOR signaling in growth and metabolism Cell 124: 471-484. https://doi.org/10.1016/j. cell.2006.01.016

Yan Y, Tsukamoto O, Nakano A, Kato H, Kioka H, Ito N, Higo S, Yamazaki S, Shintani Y, Matsuoka K, Liao Y, Asanuma H, Asakura M, Takafuji K, Minamino T, Asano Y, Kitakaze M, Takashima S (2015) Augmented AMPK activity inhibits cell migration by phosphorylating the novel substrate Pdlim5. Nat Commun 6: 6137. https://doi.org/10.1038/ncomms7137

Zhong H, Chiles K, Feldser D, Laughner E, Hanrahan C, Georgescu MM, Simons JW, Semenza GL (2000) Modulation of hypoxia-inducible factor 1alpha expression by the epidermal growth factor/ phosphatidylinositol 3-kinase/PTEN/AKT/FRAP pathway in human prostate cancer cells: implications for tumor angiogenesis and therapeutics. Cancer Res 60: 1541-1545

Zhong H, De Marzo AM, Laughner E, Lim M, Hilton DA, Zagzag D, Buechler P, Isaacs WB, Semenza GL, Simons JW (1999) Overexpression of hypoxia-inducible factor 1alpha in common human cancers and their metastases. Cancer Res 59: 5830-5835

Zhu YP, Brown JR, Sag D, Zhang L, Suttles J (2015) Adenosine 5'-monophosphate-activated protein kinase regulates IL-10-mediated anti-inflammatory signaling pathways in macrophages. I Immunol 194: 584-594. https://doi.org/10.4049/jimmunol.1401024

Zimorski V, Mentel M, Tielens AG, Martin WF (2019) Energy metabolism in anaerobic eukaryotes and Earth's late oxygenation. Free Radic Biol Med 140: 279-294. https://doi.org/10.1016/j.freeradbiomed.2019.03.030

Zumbrunn J, Kinoshita K, Hyman AA, Näthke IS (2001) Binding of the adenomatous polyposis coli protein to microtubules increases microtubule stability and is regulated by GSK3 beta phosphorylation. Curr Biol 11: 44-49. https://doi.org/10.1016/s09609822(01)00002-1

Zundel W, Schindler C, Haas-Kogan D, Koong A, Kaper F, Chen E, Gottschalk AR, Ryan HE, Johnson RS, Jefferson AB, Stokoe D, Giaccia AJ (2000) Loss of PTEN facilitates HIF-1-mediated gene expression. Genes Dev 14: 391-396 